Check for updates

Cite this: RSC Adv., 2021, 11, 1200

Received 3rd December 2020

Accepted 21st December 2020

DOI: 10.1039/dOra10194j

rsc.li/rsc-advances

\section{Tin dioxide-based nanomaterials as anodes for lithium-ion batteries}

\author{
Minkang Wang, ${ }^{a}$ Tianrui Chen, ${ }^{\mathrm{b}}$ Tianhao Liao, ${ }^{a}$ Xinglong Zhang, ${ }^{a}$ Bin Zhu, ${ }^{a}$ \\ Hui Tang (D) ${ }^{* a}$ and Changsong Dai $(\mathbb{D}$ *b
}

The development of new electrode materials for lithium-ion batteries (LIBS) has attracted significant attention because commercial anode materials in LIBs, like graphite, may not be able to meet the increasing energy demand of new electronic devices. Tin dioxide $\left(\mathrm{SnO}_{2}\right)$ is considered as a promising alternative to graphite due to its high specific capacity. However, the large volume changes of $\mathrm{SnO}_{2}$ during the lithiation/delithiation process lead to capacity fading and poor cycling performance. In this review, we have summarized the synthesis of $\mathrm{SnO}_{2}$-based nanomaterials with various structures and chemical compositions, and their electrochemical performance as LIB anodes. This review addresses pure $\mathrm{SnO}_{2}$ nanomaterials, the composites of $\mathrm{SnO}_{2}$ and carbonaceous materials, the composites of $\mathrm{SnO}_{2}$ and transition metal oxides, and other hybrid $\mathrm{SnO}_{2}$-based materials. By providing a discussion on the synthesis methods and electrochemistry of some representative $\mathrm{SnO}_{2}$-based nanomaterials, we aim to demonstrate that electrochemical properties can be significantly improved by modifying chemical composition and morphology. By analyzing and summarizing the recent progress in $\mathrm{SnO}_{2}$ anode materials, we hope to show that there is still a long way to go for $\mathrm{SnO}_{2}$ to become a commercial LIB electrode and more research has to be focused on how to enhance the cycling stability.

\section{Introduction}

Lithium-ion batteries (LIBs) have been widely used in modern electronic equipment, such as laptops, mobile phones, and mechanical devices for their high energy densities, long cycle life, and environmental friendliness. ${ }^{1-6}$ As an important component of LIBs, electrode materials are responsible for energy storage and cycling life of LIBs. ${ }^{7-11}$ Currently, graphite is the main anode in commercial LIBs owing to its good stability. ${ }^{\mathbf{1 2 - 1 4}}$ However, it cannot fully meet the increasing energy demand for batteries due to its low theoretical specific capacity $\left(372 \mathrm{~mA} \mathrm{~h} \mathrm{~g}^{-1}\right){ }^{15-18}$ In order to solve this problem, much work has been focused on exploring alternative materials with high specific capacity. ${ }^{19-26}$

Potential candidates like metal oxides have been widely researched due to their high theoretical specific capacities, such as $\mathrm{MnO},{ }^{27-30} \mathrm{MnO}_{2},{ }^{31-36} \mathrm{Mn}_{3} \mathrm{O}_{4},{ }^{37-40} \mathrm{Fe}_{2} \mathrm{O}_{3}{ }^{41-45} \mathrm{Fe}_{3} \mathrm{O}_{4},{ }^{46-50}$ $\mathrm{Co}_{3} \mathrm{O}_{4},{ }^{51-54}$ and $\mathrm{SnO}_{2} \cdot{ }^{55-57}$ Among these materials, $\mathrm{SnO}_{2}$ has attracted significant attention due to its low cost, natural abundance, and high theoretical specific capacity $\left(782 \mathrm{~mA} \mathrm{~h} \mathrm{~g}^{-1}\right.$ of bulk $\mathrm{SnO}_{2}$ ). $\mathrm{SnO}_{2}$ is superior to other metal oxides as it has a low charge and discharge potential, i.e., an average charge and

${ }^{a}$ School of Materials and Energy, University of Electronic Science and Technology of China, Chengdu, 611731, China. E-mail: tanghui@uestc.edu.cn

${ }^{b}$ School of Chemistry and Chemical Engineering, Harbin Institute of Technology, Harbin 150001, P. R. China. E-mail: changsd@hit.edu.cn discharge potential of $0.5 \mathrm{~V}$ and $0.3 \mathrm{~V} v s . \mathrm{Li} / \mathrm{Li}^{+}$, respectively, ${ }^{58}$ resulting in LIBs with higher energy density. However, the commercial use of $\mathrm{SnO}_{2}$ as an anode material is still hindered by poor cycling stability and inferior rate performance, which is attributed to the electrochemical reaction mechanism of $\mathrm{SnO}_{2}$ during lithiation/delithiation. For $\mathrm{SnO}_{2}$-based anode material for LIBs, the electrochemistry includes two steps, shown as follows: ${ }^{59-61}$

$$
\begin{gathered}
\mathrm{SnO}_{2}+4 \mathrm{Li}^{+}+4 \mathrm{e}^{-} \rightarrow \mathrm{Sn}+2 \mathrm{Li}_{2} \mathrm{O} \\
\mathrm{Sn}+x \mathrm{Li}^{+}+x \mathrm{e}^{-} \leftrightarrow \mathrm{Li}_{x} \mathrm{Sn}(0 \leq x \leq 4.4)
\end{gathered}
$$

In the first reaction, $\mathrm{SnO}_{2}$ reacts with $\mathrm{Li}^{+}$and electrons to generate $\mathrm{Sn}$ and $\mathrm{Li}_{2} \mathrm{O}$. It is believed as an irreversible process, and this is the main reason why $\mathrm{SnO}_{2}$ suffers severe capacity deterioration in the initial lithiation process. ${ }^{62}$ In the second reaction, $\mathrm{Sn}$ obtained from the first step reacts with $\mathrm{Li}^{+}$and electrons to reversibly generate $\mathrm{Li}_{x} \mathrm{Sn}$ alloys. The alloying and dealloying processes represent discharging and charging processes of $\mathrm{SnO}_{2}$-based anode material, respectively. ${ }^{63}$ However, Li-alloying anode materials like $\mathrm{Li}_{x} \mathrm{Sn}$ and $\mathrm{Li}_{x} \mathrm{Si}$, possess the disadvantages of limited cycle life and severe capacity loss because of large volume changes, pulverization, and continuous formation of solid electrolyte interphase (SEI) during the alloying/dealloying process. Therefore, owing to this irreversible phase transformation process during lithiation/ delithiation, the commercial use of $\mathrm{SnO}_{2}$ is largely hampered. 
In order to solve these problems and to improve the electrochemical performance of $\mathrm{SnO}_{2}$, researchers have synthesized many $\mathrm{SnO}_{2}$-based anode materials with various well-designed architectures. These $\mathrm{SnO}_{2}$-based anode materials can be classified into four types, according to their chemical composition. The first category includes pure nanostructured $\mathrm{SnO}_{2}$ materials, such as one-dimensional (1D) nanorods (NDs), nanotubes (NTs) ${ }^{64-68}$ and nanowires (NWs), ${ }^{69-74}$ two-dimensional nanobelts, ${ }^{75,76}$ nanosheets ${ }^{77-82}$ and nanoplates, ${ }^{83-85}$ three-dimensional (3D) hollow nanostructures, ${ }^{\mathbf{8 6}-92}$ and hierarchical nanostructures. ${ }^{93}$ Nanosized materials shorten transmission distance for electrons and $\mathrm{Li}^{+}$and also help to reduce the extent of volume changes during the electrochemical process. In addition, it has been reported that the reduction reaction of $\mathrm{SnO}_{2}$ nanomaterials becomes reversible or partly reversible, which improves the lithium storage capacity and reduces the capacity loss during the charge/discharge process. ${ }^{94}$ So the theoretic capacity of $\mathrm{SnO}_{2}$ nanomaterials can be increased up to $1495 \mathrm{~mA} \mathrm{~h} \mathrm{~g}^{-1}$. The second category includes the composites of $\mathrm{SnO}_{2}$ and carbonaceous materials, ${ }^{95-97}$ such as $\mathrm{SnO}_{2} /$ carbon nanotubes (CNTs), ${ }^{\mathbf{9 8 - 1 0 1}} \mathrm{SnO}_{2} /$ hollow carbon spheres, ${ }^{\mathbf{1 0 2}-104}$ $\mathrm{SnO}_{2}$ /graphene ${ }^{\mathbf{1 0 5 - 1 1 0}}$ and $\mathrm{SnO}_{2}$ /amorphous carbon. Carbonaceous materials improve the conductivity of the composites and also provide abundant nanosized voids as buffers to decrease the effect of large volume changes during the charge/discharge process. ${ }^{111-113}$ The third category includes the composites of $\mathrm{SnO}_{2}$, transition metal oxides, and carbonaceous materials $\left(\mathrm{SnO}_{2} / \mathrm{TMO} / \mathrm{C}\right)$. Various composites of $\mathrm{SnO}_{2}$ and transition metal oxides ( $\mathrm{SnO}_{2} / \mathrm{TMOs}$ ) have been synthesized in the past 20 years, such as $\mathrm{SnO}_{2} / \mathrm{Fe}_{2} \mathrm{O}_{3},{ }^{114-117} \quad \mathrm{SnO}_{2} / \mathrm{Co}_{3} \mathrm{O}_{4},{ }^{118,119} \quad \mathrm{SnO}_{2} /$ $\mathrm{TiO}_{2}{ }^{120-122} \mathrm{SnO}_{2} / \mathrm{ZnO}^{123}$ and $\mathrm{SnO}_{2} / \mathrm{MoO}_{3}$ (ref. 124) and they showed enhanced lithium storage capacity compared to pure $\mathrm{SnO}_{2}$ anode material. ${ }^{125}$ It has been reported that the introduction of TMOs, such as $\mathrm{Fe}_{2} \mathrm{O}_{3}$ (ref. 126) and $\mathrm{Co}_{3} \mathrm{O}_{4},{ }^{127}$ can effectively enhance the capacity because the transition metal nanoparticles in the composite can reversibly convert the extra $\mathrm{Li}_{2} \mathrm{O}$ into $\mathrm{Li}^{+}$; thus, influencing the charge/discharge processes. However, cycling stability and rate performance of the composites still need to be further improved. Therefore, based on $\mathrm{SnO}_{2}$ /TMOs materials, much work has been done to

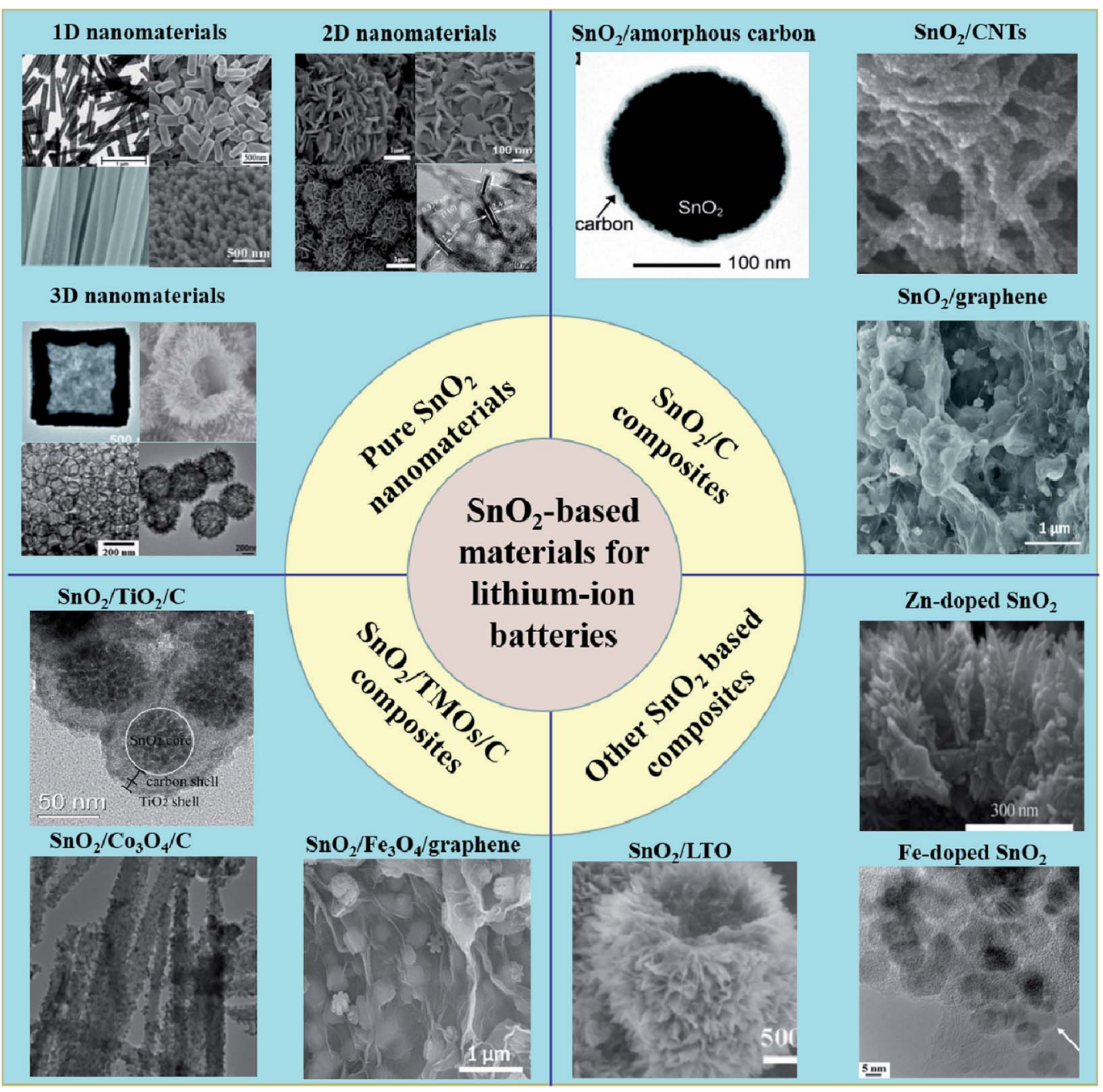

Scheme 1 Schematic presentation of different $\mathrm{SnO}_{2}$-based anode materials for LIBS. 
synthesize the composites of $\mathrm{SnO}_{2}$, TMOs, and carbonaceous materials $\left(\mathrm{SnO}_{2} / \mathrm{TMOs} / \mathrm{C}\right),{ }^{\mathbf{1 2 8 - 1 3 1}} \quad$ like $\mathrm{Fe}_{3} \mathrm{O}_{4} / \mathrm{SnO}_{2} / \mathrm{rGO},{ }^{\mathbf{1 3 2}}$ $\mathrm{SnO}_{2} @ \mathrm{C} @ \mathrm{Fe}_{3} \mathrm{O}_{4}$ (ref. 133) and $\mathrm{SnO}_{2} / \mathrm{MoO}_{3} / \mathrm{C} \cdot{ }^{\mathbf{1 3 4}, \mathbf{1 3 5}} \mathrm{SnO}_{2} / \mathrm{TMOs} /$ $\mathrm{C}$ materials more effectively alleviate the impact of volume changes and improve conductivity, leading to better electrochemical performance as an anode, compared to the $\mathrm{SnO}_{2}$ / TMOs materials. ${ }^{136,137}$ The fourth category includes some other tin dioxide-based compounds, such as heteroatom-doped $\mathrm{SnO}_{2}$ (ref. 138 and 139) (Fe-doped $\mathrm{SnO}_{2},{ }^{140} \mathrm{Zn}$-doped $\mathrm{SnO}_{2}$ (ref. 141)), $\mathrm{Li}_{4} \mathrm{Ti}_{5} \mathrm{O}_{12} / \mathrm{SnO}_{2}$ (ref. 142) and $\mathrm{SnO}_{2} / \mathrm{C}_{3} \mathrm{~N}_{4} \cdot{ }^{143}$

In this article, we provide the recent progress in the research of these four major types of $\mathrm{SnO}_{2}$-based anode material, as mentioned above (Scheme 1). For the following sections, we will introduce the various $\mathrm{SnO}_{2}$-based nanomaterials as well as their corresponding synthesis methods and electrochemical performance. We hope this review article will serve as a good reference for further research.

\section{Pure nanostructured $\mathrm{SnO}_{2}$ materials}

\subsection{D nanomaterials}

Many 1D nanostructured $\mathrm{SnO}_{2}$ materials, such as nanorods, ${ }^{144-146}$ nanotubes ${ }^{147-150}$ and nanowires ${ }^{151-153}$ have been synthesized in recent years. $1 \mathrm{D} \mathrm{SnO}_{2}$ nanomaterials usually exhibit superior specific discharge capacity since they can offer extra channels and pathways for electron transmission compared to bulk $\mathrm{SnO}_{2}$ and $\mathrm{SnO}_{2}$ powders. ${ }^{154-156}$

2.1.1 $\mathrm{SnO}_{2}$ nanorods. Pure $\mathrm{SnO}_{2}$ nanorods can be synthesized via many methods such as chemical vapor deposition (CVD), vapor liquid solid, ${ }^{157}$ hydrothermal treatment ${ }^{158}$ and spray pyrolysis approach. ${ }^{159}$ Among these reported methods, the hydrothermal synthesis of $\mathrm{SnO}_{2}$ nanorods is the most used routine as it can be conveniently controlled due to its facile operation. The formation mechanism in a hydrothermal system can be summarized as follows:

$$
\mathrm{Sn}^{4+}+4 \mathrm{OH}^{-} \rightarrow \mathrm{Sn}(\mathrm{OH})_{4} \rightarrow \mathrm{SnO}_{2}+2 \mathrm{H}_{2} \mathrm{O}
$$

First, $\mathrm{Sn}(\mathrm{OH})_{4}$ forms by the hydrolysis of Sn-based salts in aqueous medium. During the hydrothermal treatment, $\mathrm{Sn}(\mathrm{OH})_{4}$ tends to convert into $\mathrm{SnO}_{2}$ and subsequently grows along the [001] direction. ${ }^{\mathbf{1 6 0 , 1 6 1}}$ Early in 2003, Zhang et al. fabricated uniform $\mathrm{SnO}_{2}$ nanorods with diameters of about 8-15 $\mathrm{nm}$ and lengths of about 150-200 $\mathrm{nm}$ by a one-step procedure under mild conditions. ${ }^{148}$ They dissolved sodium dodecyl sulfate and $\mathrm{Sn}(\mathrm{OH})_{6}{ }^{2-}$ salt in a solution consisting of heptane and hexanol by stirring. Then, the homogeneously dispersed solution was transferred into a Teflon-lined autoclave and heated to $200{ }^{\circ} \mathrm{C}$ for $18 \mathrm{~h}$. The as-prepared $\mathrm{SnO}_{2}$ nanorods displayed a crystalline rutile structure. Zhang et al. also discovered that the concentration of $\mathrm{Sn}(\mathrm{OH})_{6}{ }^{2-}$ ions and the ratio of $\mathrm{NaOH}$ and $\mathrm{SnCl}_{4}$ determined the shape of the $\mathrm{SnO}_{2}$ nanorods. It was found that on increasing the concentration of $\mathrm{Sn}(\mathrm{OH})_{6}{ }^{2-}$ from $0.2 \mathrm{M}$ to $0.3 \mathrm{M}$, the number of nanorods significantly decreased; additionally, on increasing the molar ratio of $\mathrm{NaOH}$ to $\mathrm{SnCl}_{4}$ from $10: 1$ to $30: 1$, the aspect ratio of $\mathrm{SnO}_{2}$ nanorods increased. ${ }^{162}$
In 2004, Cheng et al. investigated a large-scale hydrothermal method to synthesize single-crystalline $\mathrm{SnO}_{2}$ nanorods with lengths of 15-20 nm and diameters of 2.5-5 nm (Fig. 1A). $\mathrm{Sn}^{4+}$ precursor was dissolved in a mixture of water and alcohol, and $\mathrm{pH}$ was adjusted 12 and the solution was then heated at $150{ }^{\circ} \mathrm{C}$ for 24 h. $^{163}$ Based on Zhang and Cheng's work, many groups have synthesized $\mathrm{SnO}_{2}$ nanorods via hydrothermal methods in other different systems. Guo et al. synthesized $\mathrm{SnO}_{2}$ nanorods with diameter in the range of 120-260 nm and length up to 2-3 $\mu \mathrm{m}$ by using hexadecyltrimethylammonium bromide as a template (Fig. 1B). ${ }^{58}$ Chen et al. synthesized single crystalline $\mathrm{SnO}_{2}$ nanorods with diameters of 4-15 nm and lengths of 100$200 \mathrm{~nm} .{ }^{\mathbf{1 4 5}} \mathrm{Xi}$ et al. investigated a new synthesis method of ultrathin $\mathrm{SnO}_{2}$ nanorods with an average diameter of $2 \pm$ $0.5 \mathrm{~nm} .{ }^{164}$ Therefore, various $\mathrm{SnO}_{2}$ nanorods with distinct morphology can be synthesized by controlling hydrothermal conditions.

$\mathrm{SnO}_{2}$ nanorods can be applied as anode materials in LIBs. ${ }^{\mathbf{1 6 5}}$ Liu et al. synthesized $\mathrm{SnO}_{2}$ nanorods arrays on a flexible alloy substrate via hydrothermal method. The nanorods arrays have average diameter and length of 60 and $670 \mathrm{~nm}$, respectively (Fig. 1C). Observed by HRTEM images (Fig. 1D) and FFT pattern of HRTEM images (Fig. 1E), $\mathrm{SnO}_{2}$ nanorod array was growing on substrate along [001] direction, since (001) plane is more loosely packed and has a relatively high surface energy compared to $\{110\}$ planes. ${ }^{166}$ As-collected hierarchical array structure can directly be used as a binder-free electrode for LIBs, which shows good energy performance, including high discharge capacity

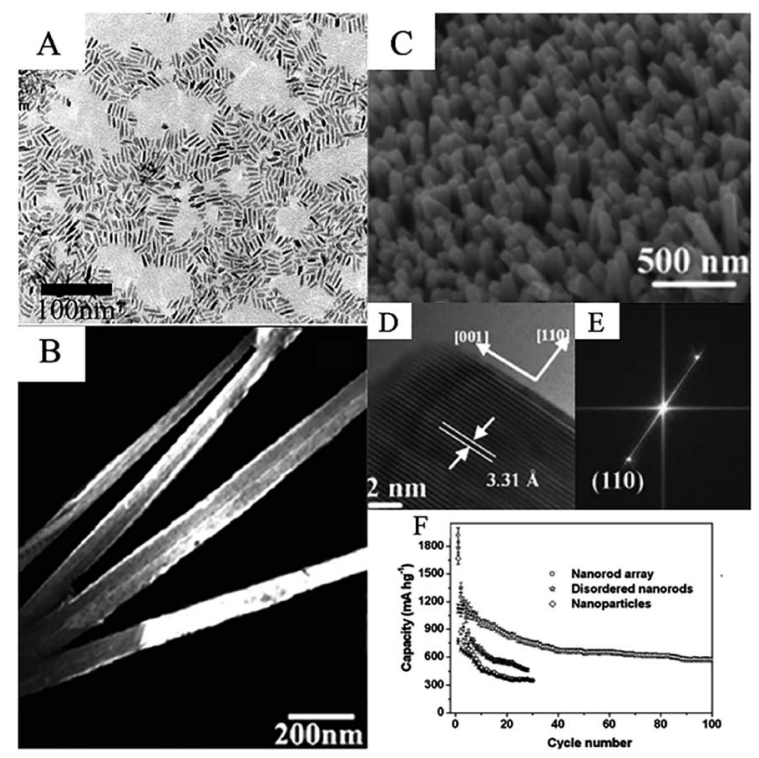

Fig. 1 (A) Transmission electron microscopy (TEM) images of the asprepared $\mathrm{SnO}_{2}$ nanorods (adapted with permission from ref. 163 copyright 2004 American Chemical Society). (B) Scanning electron microscopy (SEM) images of long $\mathrm{SnO}_{2}$ nanorods (adapted with permission from ref. 58 copyright 2004 Elsevier). (C) SEM images, (D) high-resolution TEM (HRTEM) images, (E) FFT patterns of the HRTEM images, and (F) cycling performance of $\mathrm{SnO}_{2}$ nanorods (adapted with permission from ref. 154 copyright 2009 Royal Society of Chemistry). 
(the first discharge is $1918 \mathrm{~mA} \mathrm{~h} \mathrm{~g}^{-1}$ ) and good cycling stability (580 $\mathrm{mA} \mathrm{h} \mathrm{g}^{-1}$ after 100 cycles at $0.1 \mathrm{C}$, with coulombic efficiency of nearly $100 \%$ ) (Fig. 1F). ${ }^{154}$

2.1.2 $\mathrm{SnO}_{2}$ nanotubes. $\mathrm{SnO}_{2}$ nanotubes have been widely used as anode materials in lithium-ion batteries. Compared to $\mathrm{SnO}_{2}$ nanorods, $\mathrm{SnO}_{2}$ nanotubes usually possess superior lithium storage capacity and cycling stability due to their hollow characteristics. ${ }^{167}$ Sacrificial template-based approaches are commonly used in synthesizing this tubular structure. Anodic aluminum anode (AAO), polycarbonate (PC) membrane, $\mathrm{SiO}_{2}$ and $\mathrm{ZnO}$ can be served as sacrificial templates in synthesizing metal oxides nanostructures. The synthesis process of $\mathrm{SnO}_{2}$ nanotubes usually includes three steps: (1) infiltration of reactants into the templates; (2) growth of $\mathrm{SnO}_{2}$ with designed shapes and morphology; (3) removal of the template.

Early in 2006, Lai et al. reported the preparation of $\mathrm{SnO}_{2}$ nanotubes with a thickness of $10 \mathrm{~nm}$ and a length of about $0.4-$ $1.4 \mu \mathrm{m}$ via the electrodeposition method (Fig. 2A). They first electroplated the $\mathrm{SnO}_{2}$ nanoparticles on a gold electrode which was modified with a porous $\mathrm{PC}$ membrane. Then, the $\mathrm{SnO}_{2}$ particles were annealed at $650{ }^{\circ} \mathrm{C}$ in ambient conditions. The shape and size of the as-prepared nanotubes could be easily controlled by monitoring the charge passed. ${ }^{66}$ Meanwhile, Lai et al. also reported that the $\mathrm{SnO}_{2}$ nanotubes possessed better crystallinity and uniformity in terms of length and width.

The AAO and PC membrane-template methods have been widely used in the synthesis of metal oxide nanotubes. Wang et al. fabricated uniform polycrystalline $\mathrm{SnO}_{2}$ nanotubes via this template. ${ }^{68}$ They found that the diameter, thickness, length,

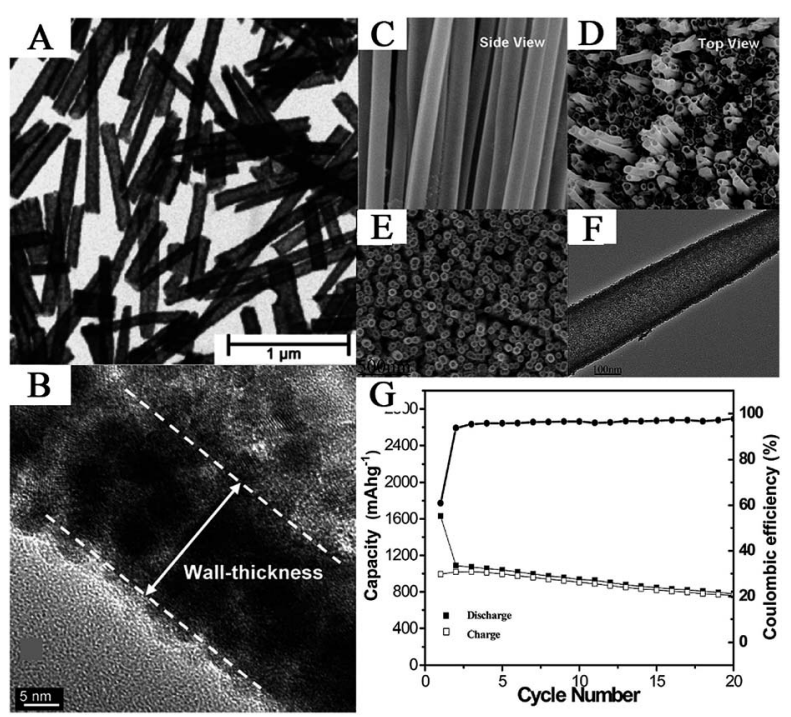

Fig. 2 (A) TEM image of $\mathrm{SnO}_{2}$ nanotubes (adapted with permission from ref. 66 copyright 2006 Royal Society of Chemistry). (B) HRTEM image of $\mathrm{SnO}_{2}$ nanotubes for measuring thickness, (C) FESEM image of the side view, and (D) FESEM images of the top view of $\mathrm{SnO}_{2}$ nanotubes (adapted with permission from ref. 68 copyright 2005 American Chemical Society). (E) TEM image, (F) HRTEM image, and (G) discharge capacity vs. cycle number of $\mathrm{SnO}_{2}$ nanotube arrays on Ti substrates (adapted with permission from ref. 64 copyright 2011 American Chemical Society). and texture of nanotubes can be controlled with template structure, pristine particle size, and heating-rate temperature. As shown in Fig. 2B-D, nanotube walls, with a thickness of about 10-25 nm, were composed of abundant nanocrystallites of 6-15 nm. Furthermore, the $\mathrm{SnO}_{2}$ nanotube electrode showed superior charge/discharge performance compared to $\mathrm{SnO}_{2}$ nanoparticles. The specific capacity of the $\mathrm{SnO}_{2}$ nanotube electrode can be $525 \mathrm{~mA} \mathrm{~h} \mathrm{~g}{ }^{-1}$ after 80 cycles. $^{68}$ They summarized that the improved cycling performance resulted from the following factors, (1) cavities in the nanotubes which provide space and reduce the effect of volume change during lithiation/ delithiation process; (2) $\mathrm{SnO}_{2}$ nanotubes provide more active sites for $\mathrm{Li}^{+}$intercalation and deintercalation; and (3) compared to $\mathrm{SnO}_{2}$ nanoparticles, the $\mathrm{SnO}_{2}$ nanotubes are less movable and result in less agglomeration. ${ }^{68} \mathrm{Si}$ and $\mathrm{SiO}_{2}$ have been commonly used in the synthesis of hollow nanostructures, including nanotubes. Morphology and shapes of $\mathrm{SnO}_{2}$ nanotubes can be well designed by controlling the shape of the $\mathrm{Si}$ templates and the hydrothermal conditions. ${ }^{168}$ Ye et al. also discovered that the shorter $\mathrm{SnO}_{2}$ nanotubes showed superior electrochemical performance, since the hollow structure in the short nanotubes can alleviate the volume changes. ${ }^{147} \mathrm{ZnO}$ is another promising sacrificial template used for synthesizing $\mathrm{SnO}_{2}$ nanotube arrays as $\mathrm{ZnO}$ can be conveniently synthesized and removed. The as-prepared nanotubes exhibited a diameter and thickness of about 100-300 $\mathrm{nm}$ and about 10-20 nm, respectively, composed of nanoparticles with diameters of about 2-5 nm (Fig. 2E and F). The material also showed high capacity and improved cycling performance, i.e., 750$800 \mathrm{~mA} \mathrm{~h} \mathrm{~g}^{-1}$ after 20 cycles at $0.1 \mathrm{C}$, as shown in Fig. 2G. ${ }^{64}$

2.1.3 $\mathrm{SnO}_{2}$ nanowires. Template-based methods have also been widely used to synthesize $\mathrm{SnO}_{2}$ nanowires. These sacrificial templates contribute to the development of mesoporous and hollow $\mathrm{SnO}_{2}$ nanowires. ${ }^{\mathbf{6 3 , 1 6 9}} \mathrm{Kim}$ et al. fabricated a $\mathrm{SnO}_{2}$ nanowire-based anode material for LIBs by using KIT-6 and SBA-15 $\mathrm{SiO}_{2}$ as hard templates. They first dissolved $\mathrm{SnCl}_{4} \cdot 5 \mathrm{H}_{2} \mathrm{O}$ and the hard templates in DI water and stirred the mixture at room temperature until $\mathrm{Sn}^{4+}$ was adsorbed by templates. Then, the resulting composites were annealed, and the templates were removed from the composites using a $\mathrm{NaOH}$ solution. The asobtained $\mathrm{SnO}_{2}$ nanowires had a diameter of $6 \mathrm{~nm}$ and a length greater than $3 \mu \mathrm{m}$, and the size of mesoporous $\mathrm{SnO}_{2}$ on the surface of the nanowire was $3.8 \mathrm{~nm}$ with a BET surface area of $160 \mathrm{~m}^{2} \mathrm{~g}^{-1}$. Such a porous and interconnected $\mathrm{SnO}_{2}$ nanowire structure showed better lithium storage capacity. The initial discharge and charge capacities of the nanowire anode were 1595 and $800 \mathrm{~mA} \mathrm{~h} \mathrm{~g}^{-1}$ at $0.2 \mathrm{C}$, respectively, and the discharge capacity remained at $773 \mathrm{~mA} \mathrm{~h} \mathrm{~g}{ }^{-1}$ after 50 cycles. These observations can be attributed to the mesopores which act as a buffer zone against $\mathrm{SnO}_{2}$ volume expansion. ${ }^{71}$

Researchers have synthesized $\mathrm{SnO}_{2}$ nanowires via many methods. For example, Ko et al. synthesized $\mathrm{SnO}_{2}$ nanowires on the current collector via thermal evaporation at $\left(600^{\circ} \mathrm{C}\right)$. The asprepared $\mathrm{SnO}_{2}$ nanowires exhibited a highly-ordered singlecrystalline phase with a thin diameter of 40-50 nm and length of more than $1 \mu \mathrm{m}$ (Fig. 3A and $\mathrm{B}$ ). The $\mathrm{SnO}_{2}$ nanowire-based anode exhibited high specific discharge capacity and good 


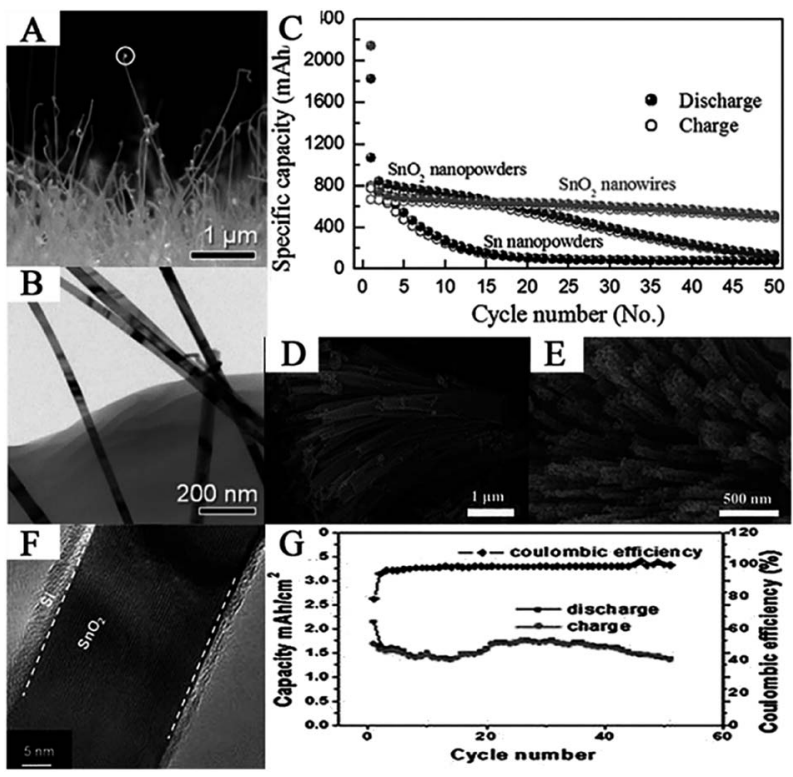

Fig. 3 (A) Cross-sectional FESEM image, (B) TEM image, and (C) comparative cycling performance of the $\mathrm{SnO}_{2}$ nanowires (adapted with permission from ref. 72 copyright 2009 IOP Publishing). (D and E) SEM images of $\mathrm{SnO}_{2}$ porous nanowire bundles (adapted with permission from ref. 170 copyright 2011 Royal Society of Chemistry). (F) HRTEM image, and (G) cycling performance of the $\mathrm{SnO}_{2} \mathrm{QSi}$ nanowires (adapted with permission from ref. 73 copyright 2013 Royal Society of Chemistry)

cycling performance, i.e., $2140 \mathrm{~mA} \mathrm{~h} \mathrm{~g}{ }^{-1}$ at the first cycle and $510 \mathrm{~mA} \mathrm{~h} \mathrm{~g}^{-1}$ at the $50^{\text {th }}$ cycle at $1 \mathrm{C}$ (Fig. 3C)..$^{72}$ Ding et al. reported a facile strategy for the synthesis of $\mathrm{SnO}_{2}$ nanowire arrays using SBA-15 nanorods as a template by infiltrating molten $\mathrm{SnCl}_{2}$ into the channels of the SBA- 15 nanorods followed by calcination and removal of the template. ${ }^{69}$ Han et al. investigated the synthesis of porous $\mathrm{SnO}_{2}$ nanowire bundles with a high yield via solution-based approaches. This hierarchical nanostructure is made up of $\mathrm{SnO}_{2}$ nanowires with an overall diameter of $80-120 \mathrm{~nm}$ and an average length of $6 \mu \mathrm{m}$ (Fig. 3D). Moreover, the as-prepared nanowires have a highly porous structure composed of numerous nanocrystals. ${ }^{\mathbf{1 7 0}}$ Ren et al. synthesized 3D hierarchical $\mathrm{SnO}_{2}$ nanowire arrays on carbon cloth by first, a CVD method for $\mathrm{SnO}_{2}$ nanowires, followed by a Plasma Enhanced-CVD (PECVD) method for Si thin film coating. The $\mathrm{SnO}_{2} @ \mathrm{Si}$ nanowire arrays can directly serve as a flexible and binder-free anode for LIBs. In this unique structure, $\mathrm{SnO}_{2}$ nanowires act as a lithium storage material and a conductive matrix to support $\mathrm{Si}$; in addition, the thin $\mathrm{Si}$ layer acts as a buffer for $\mathrm{SnO}_{2}$ to reduce the effect of volume changes (Fig. 3F). Anodes based on such novel hierarchical structures showed excellent electrochemical performance with discharge capacity of $2.13 \mathrm{~mA} \mathrm{~h} \mathrm{~cm}{ }^{-2}$ in the first cycle and $1.386 \mathrm{~mA} \mathrm{~h} \mathrm{~cm}{ }^{-2}$ after 50 cycles, i.e., $65 \%$ of the first cycle (Fig. 3G). ${ }^{73}$ Thus, in this section, different synthesis methods for $\mathrm{SnO}_{2}$ nanowires, corresponding morphologies, and electrochemical properties have been presented, demonstrating that $\mathrm{SnO}_{2}$ nanowires are promising anode materials for LIBs.

\subsection{D nanomaterials}

Due to the difficulty of synthesizing well-defined $2 \mathrm{D} \mathrm{SnO}_{2}$ nanomaterials, obtaining a large variety of $2 \mathrm{D}^{\mathrm{SnO}_{2}}$ nanostructures is significantly harder than $1 \mathrm{D}$ and $3 \mathrm{D}$ nanomaterials. The anisotropic crystal growth of $\mathrm{SnO}_{2}$, in the formation process, limits the synthesis of $2 \mathrm{D}$ nanomaterials. ${ }^{82}$ In order to overcome this problem, in situ growth of $\mathrm{SnO}_{2}$ nanosheets on physical or chemical substrates has been widely investigated. ${ }^{171,172}$ Among these fabrication processes, $\mathrm{SnO}_{2}$ nanosheets grown on physical substrates, such as metal foam, ${ }^{49,173-175}$ foil, ${ }^{77,154,176-178}$ carbon cloth $^{78,179}$ and graphite paper $^{180-183}$ can be directly used as binder-free and currentcollector free electrode in LIBs due to excellent conductive and supportive properties of such substrates. Meanwhile, some organic macromolecules can be used as chemical templates to fabricate $\mathrm{SnO}_{2}$ nanosheets. These substrates could provide a growth plane for $\mathrm{SnO}_{2}$ nanosheets and inhibit selfaggregation during the lithiation/delithiation processes. ${ }^{184}$ Moreover, $\mathrm{SnO}_{2}$ nanosheets have a tendency to assemble into complex structures, such as nanosheet arrays, clusters, and spheres, which usually exhibit superior lithium storage capacities due to their highly interconnected and hierarchical nanostructures. ${ }^{184-187}$

Zhao et al. fabricated $\mathrm{SnO}_{2}$ nanosheet arrays on $\mathrm{Ni}$ foam with a thickness of $20 \mathrm{~nm}$ and a length of $500 \mathrm{~nm}$ (Fig. 4A) via a hydrothermal method. Nickel foam, i.e., a 3D macroporous conductive network, was used as a supportive substrate to fabricate $\mathrm{SnO}_{2}$ nanosheet arrays, which can be directly used as a binder-free anode in LIBs. Due to the high electroactive surface area, ultrathin sheets, and shorter electron transport pathways, the nanosheets exhibited excellent electrochemical properties. The novel anode showed an initial discharge capacity of approximately $1800 \mathrm{~mA} \mathrm{~h} \mathrm{~g}{ }^{-1}$ and remained at $674.9 \mathrm{~mA} \mathrm{~h} \mathrm{~g}^{-1}$ after 50 cycles at $0.5 \mathrm{C}$ (Fig. 4B). ${ }^{79}$ Moreover,

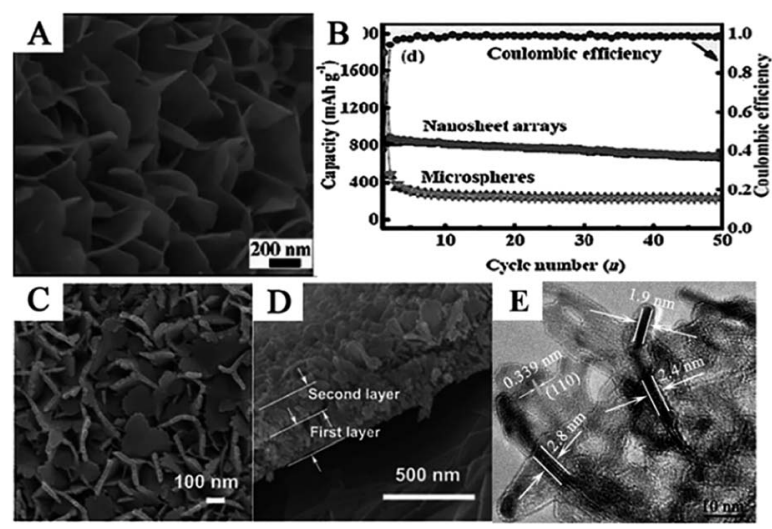

Fig. 4 (A) SEM image, and (B) cycling performance of hierarchical $\mathrm{SnO}_{2}$ nanosheet arrays on nickel foam (adapted with permission from ref. 79 copyright 2014 Wiley). (C) Top view, and (D) cross-sectional FESEM images of $\mathrm{SnO}_{2}$ nanosheets double layer on Ti foil (adapted with permission from ref. 77 copyright 2014 Royal Society of Chemistry). (E) HRTEM image of ultrathin $\mathrm{SnO}_{2}$ nanosheets of less than $5 \mathrm{~nm}$ (adapted the permission from ref. 80 copyright 2015 American Chemical Society). 
interconnected single and double layer $\mathrm{SnO}_{2}$ nanosheets were also fabricated on three different conductive substrates, i.e., Ti, $\mathrm{Cu}$ foil, and flexible graphite paper, as integrated binder-free electrodes for LIBs. The nanosheets were interconnected with each other to form a hierarchical network, and the thickness of a single $\mathrm{SnO}_{2}$ nanosheet layer was about $250 \mathrm{~nm}$ (Fig. 4C and D). The electrodes delivered high specific capacity, excellent cycling stability, and good rate capability. ${ }^{77,79} \mathrm{Zhu}$ et al. reported an ultra-rapid, low-cost, and simple microwave-assisted synthesis of ultrathin $\mathrm{SnO}_{2}$ nanosheets with a thickness of less than $5 \mathrm{~nm}$ (Fig. 4E). The ultrathin $\mathrm{SnO}_{2}$ nanosheets exhibited significantly enhanced electrochemical lithium storage properties with a high reversible capacity of $757.6 \mathrm{~mA} \mathrm{~h} \mathrm{~g}^{-1}$ at a current density of $200 \mathrm{~mA} \mathrm{~g}^{-1}$ up to 40 cycles. The ultrathin 2D nanosheets can significantly reduce the ion diffusion paths and allow faster phase transitions; furthermore, the sufficient external surface interspace and porous configuration successfully accommodate the large volume changes. ${ }^{77,78,80}$

Many complex hierarchical $\mathrm{SnO}_{2}$ nanostructures were also assembled by $2 \mathrm{D} \mathrm{SnO}_{2}$ nanosheets. Flower-like $\mathrm{SnO}_{2}$ assembled by many $\mathrm{SnO}_{2}$ nanosheets, with an average thickness of $100 \mathrm{~nm}$, have been synthesized on a flexible carbon cloth using CVD at $750{ }^{\circ} \mathrm{C}^{78} \mathrm{SEM}$ images (Fig. 5A) show that as-prepared flower-like $\mathrm{SnO}_{2}$ nanostructures were formed by an assembly of numerous nanosheets with a thickness of $100 \mathrm{~nm}$. Ding et al. synthesized hollow spheres assembled from $\mathrm{SnO}_{2}$ nanosheets (Fig. 5B), using sulfonated polystyrene hollow spheres (sPSHSs) as a template; the surface of the sPSHS is covered with $-\mathrm{SO}_{3}-$ functional groups. Therefore, the $\mathrm{Sn}^{2+}$ ions can easily interact with these templates via electrostatic forces and subsequently grow into $\mathrm{SnO}_{2}$ nanosheets, assisted by mercaptoacetic acid. Moreover, sPSHSs templates are beneficial for minimizing the gas outflux during the template removal process, which helps the retention of the final structure. ${ }^{\mathbf{1 8 8 - 1 9 1}}$ The as-prepared

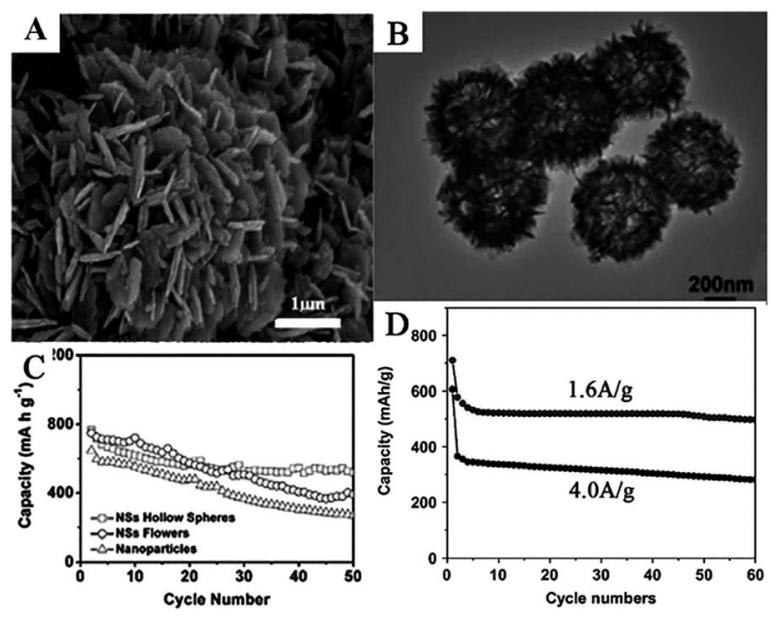

Fig. 5 (A) SEM images of flower-like $\mathrm{SnO}_{2}$ nanosheets (adapted with permission from ref. 78 copyright 2014 Elsevier). (B) TEM image, and (C) cycling performance of $\mathrm{SnO}_{2}$ nanosheets hollow spheres (adapted the permission from ref. 87 copyright 2011 Royal Society of Chemistry). (D) Cycling performance of $\mathrm{SnO}_{2}$ nanosheets at $1.6 \mathrm{~A} \mathrm{~g}^{-1}$ and $4.0 \mathrm{~A} \mathrm{~g}^{-1}$ (adapted the permission from ref. 81 copyright 2017 Elsevier). samples showed a superior cycling capacity retention compared to other $\mathrm{SnO}_{2}$ nanoflowers assembled by $\mathrm{SnO}_{2}$ nanosheets as well as $\mathrm{SnO}_{2}$ nanoparticles, indicating the positive effect of the unique nanostructure (Fig. 5C). ${ }^{87}$ Wei et al. fabricated nanoporous $\mathrm{SnO}_{2}$ nanosheets via a simple one-step ultrasonicassisted chemical precipitation strategy with polyvinylpyrrolidone (PVP) as a soft template. Due to the porous nanosheet structure, it exhibited high capacity, i.e., an initial discharge capacity of $2231 \mathrm{~mA} \mathrm{~h} \mathrm{~g}^{-1}$ at $0.2 \mathrm{~A} \mathrm{~g}^{-1}$, and excellent cycling performance, i.e., an initial discharge capacity of $710 \mathrm{~mA} \mathrm{~h} \mathrm{~g}^{-1}$ and $606 \mathrm{~mA} \mathrm{~g}^{-1}$ at $1.6 \mathrm{~A} \mathrm{~g}^{-1}$ and $4 \mathrm{~A} \mathrm{~g}^{-1}$, respectively, which remained at $497 \mathrm{~mA} \mathrm{~h} \mathrm{~g}^{-1}$ and $280 \mathrm{~mA} \mathrm{~h} \mathrm{~g}^{-1}$ after 60 cycles, respectively (Fig. 5D). ${ }^{81}$

\subsection{D nanomaterials}

In recent years, 3D $\mathrm{SnO}_{2}$ structures have attracted significant attention. ${ }^{86}$ Various 3D nanostructures have been synthesized, such as hollow spheres ${ }^{\mathbf{9 1 , 1 9 2 - 1 9 4}}$ and microboxes. ${ }^{\text {195-197 }}$ Furthermore, many new synthetic methods to prepare $\mathrm{SnO}_{2}$ hollow structures, including Ostwald ripening, ${ }^{\text {198-200 }}$ Kirkendall effect, ${ }^{201-204}$ removable templates ${ }^{195}$ and chemically induced selfassembly ${ }^{192,205}$ have been reported.

In 2006, Lou et al. investigated a one-pot template-free synthesis of hollow $\mathrm{SnO}_{2}$ nanostructures, based on an unusual inside-out Ostwald ripening mechanism. The synthesis process was performed in an ethanol-water $\left(\mathrm{EtOH}-\mathrm{H}_{2} \mathrm{O}\right)$ mixed solvent with $\mathrm{K}_{2} \mathrm{SnO}_{3}$ as the precursor, followed by a hydrothermal treatment. Lou et al. discovered that the concentration of the precursor and the ratio of $\mathrm{EtOH}$ in the mixed solvent determined both the particle size and morphology of the product. Moreover, the addition of urea or thiourea in the synthetic mixtures was also found to increase the product yield, morphological yield to nearly $100 \%$, and a well-dispersed monodispersity (Fig. 6A-C). Such hollow $\mathrm{SnO}_{2}$ nanospherebased anode material exhibited high discharge capacity and good cycling performance, i.e., an initial discharge capacity of $1140 \mathrm{~mA} \mathrm{~h} \mathrm{~g}^{-1}$, which is comparable to the theoretical capacity of graphite after more than 40 cycles. $^{86}$

Porous hollow $\mathrm{SnO}_{2}$ micro-boxes have been synthesized via a selective leaching strategy using $\mathrm{ZnSn}(\mathrm{OH})_{6}$ as the precursor. $\mathrm{ZnSn}(\mathrm{OH})_{6}$ micro-boxes were first formed through a modified one-pot co-precipitation method and subsequently, the $\mathrm{Zn}$ species were removed via a selective leaching strategy. The TEM image (Fig. 6D) shows that the thickness of the shell was about $100 \mathrm{~nm} .{ }^{195} \mathrm{Hu}$ et al. used a template-and additive-free hydrothermal route to prepare a uniquely shaped $\mathrm{SnO}_{2}$ material that comprised of a hollow spherical morphology with uniform diameter and very thin petal-like nanosheets grown perpendicularly on the surface of the spheres, resembling a "chestnut cupule" (Fig. 6E). In contrast to conventional $\mathrm{SnO}_{2}$ materials, this unique morphology significantly improved the storage capacity and cycling performance of $\mathrm{SnO}_{2}$ as an anode material for lithium and sodium ion batteries. ${ }^{206}$

In addition, 3D hierarchical $\mathrm{SnO}_{2}$ nanomaterials can be assembled by $0 \mathrm{D}, 1 \mathrm{D}$, and $2 \mathrm{D} \mathrm{SnO}_{2}$ nanomaterials. For example, oD crystalline $\mathrm{SnO}_{2}$ nanoparticles were successfully assembled 

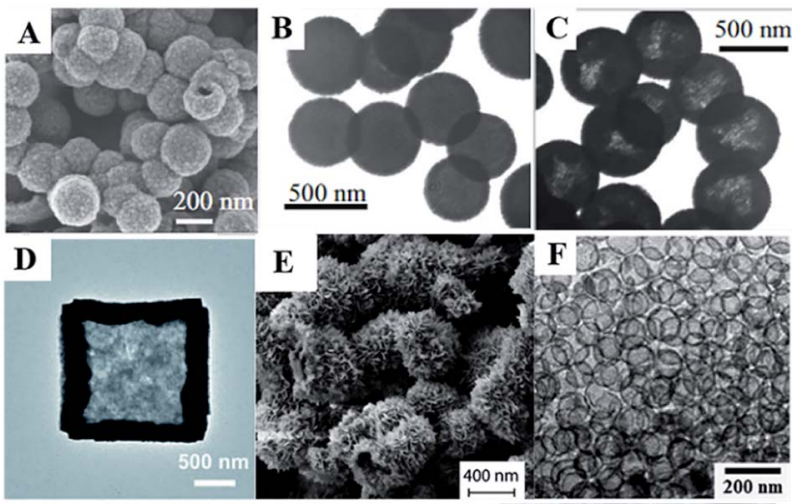

$\mathbf{E}$
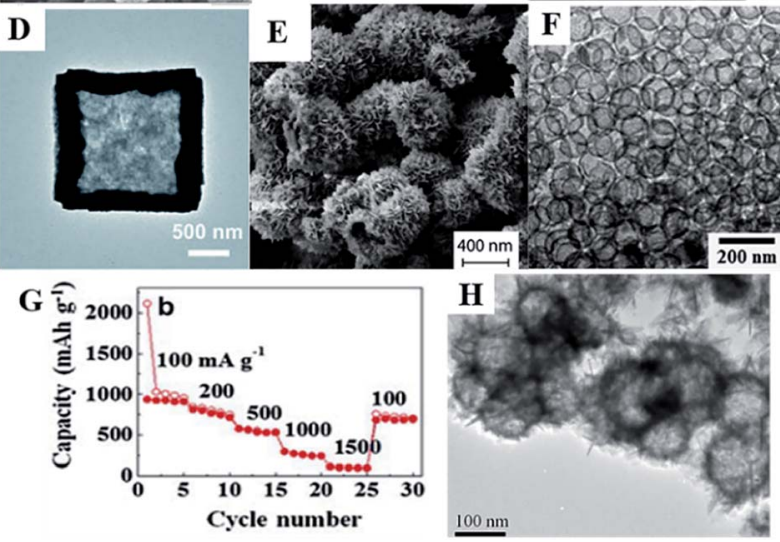

Fig. 6 (A) FESEM images of $\mathrm{SnO}_{2}$ hollow nanosphere prepared in the solvent of EtOH : $\mathrm{H}_{2} \mathrm{O}$ ratio of $1: 1$. (B) TEM images of $\mathrm{SnO}_{2}$ hollow nanosphere prepared with the value of $\mathrm{EtOH}$ in the solvent of $\mathrm{EtOH}-$ $\mathrm{H}_{2} \mathrm{O}=37.5 \%$. (C) TEM images of $\mathrm{SnO}_{2}$ hollow nanosphere prepared with the value of $\mathrm{EtOH}$ in the solvent $\mathrm{EtOH}-\mathrm{H}_{2} \mathrm{O}=37.5 \%$ and $0.1 \mathrm{M}$ urea (adapted the permission from ref. 86 copyright 2006 WILEY). (D) TEM images of $\mathrm{SnO}_{2}$ microboxes (adapted the permission from ref. 195 copyright 2016 Royal Society of Chemistry). (E) SEM images of $\mathrm{SnO}_{2}$ hierarchical hollow microspheres (adapted the permission from ref. 205 copyright 2017 Royal Society of Chemistry). (F) TEM images, and (G) rate performance of $\mathrm{SnO}_{2}$ hollow spheres (adapted with permission from ref. 91 copyright 2012 Elsevier). (H) TEM image of the hierarchical $\mathrm{SnO}_{2}$ (adapted with permission from ref. 210 copyright 2010 American Chemical Society).

into a high-order nanostructure of hollow core-shell. First, $\mathrm{SnCl}_{4}$ was dissolved in a mixture of DI water and ethanol to form a homogeneous solution which was heated to $180{ }^{\circ} \mathrm{C}$ for $24 \mathrm{~h}$. Then, the collected sediments were calcined in air to remove carbon by oxidation. FESEM showed that the mesospheres had an overall dimension of 1-3 $\mu \mathrm{m}$, and the surface of the spheres was formed by small aggregated $\mathrm{SnO}_{2}$ nanoparticles $(11 \mathrm{~nm})$. The shell was estimated to be approximately $200 \mathrm{~nm}$ in thickness. This unique $\mathrm{SnO}_{2}$ nanostructure could store an exceedingly large amount of $\mathrm{Li}^{+}$and cycled well for a pure phase $\mathrm{SnO}_{2}$ anode. ${ }^{\text {207-209}}$ Hollow urchin-like $\mathrm{SnO}_{2}$ nanospheres have been fabricated using ultrathin nanorods via a solvothermal route. The diameters of urchin-like nanospheres and nanorods are about 300 and $100 \mathrm{~nm}$, respectively. The asobtained hollow urchin-like $\mathrm{SnO}_{2}$ nanospheres with ultrathin 1D nanorods exhibited high capacity and excellent rate discharging performance. The $1^{\text {st }}, 2^{\text {nd }}, 20^{\text {th }}$, and $50^{\text {th }}$ discharge capacities were $1881 \mathrm{~mA} \mathrm{~h} \mathrm{~g}^{-1}, 1090 \mathrm{~mA} \mathrm{~h} \mathrm{~g}{ }^{-1}, 781 \mathrm{~mA} \mathrm{~h} \mathrm{~g}^{-1}$, and $719 \mathrm{~mA} \mathrm{~h} \mathrm{~g}{ }^{-1}$, respectively, at a current density of $100 \mathrm{~mA} \mathrm{~g}^{-1}$. Upon changing the discharge-charge rates to 0.2 , $0.4,0.8,1,2$, and $0.4 \mathrm{C}$, the capacities of urchin-like $\mathrm{SnO}_{2}$ were maintained at $815,687,601,446,282$, and $520 \mathrm{~mA} \mathrm{~h} \mathrm{~g}{ }^{-1}$, respectively, while for commercial $\mathrm{SnO}_{2}$, the capacities were only $828,677,512,386,246,133$, and $375 \mathrm{~mA} \mathrm{~h} \mathrm{~g}^{-1}$, respectively. The retention of the reversible capacity of the hollow nanosphere electrodes was better than that of commercial $\mathrm{SnO}_{2}$ samples. ${ }^{210}$ Furthermore, $\mathrm{SnO}_{2}$ hollow nanospheres can also be synthesized by sol-gel methods. ${ }^{91}$ The size of the hollow spheres is controlled by using different-sized templates. As-prepared $\mathrm{SnO}_{2}$ shells are almost amorphous and exhibit a rutile phase after annealing at $600{ }^{\circ} \mathrm{C}$. The size of the $\mathrm{SnO}_{2}$ hollow spheres ranges from 25 to $100 \mathrm{~nm}$ (Fig. 6F), and the thickness of the shell is constantly $5 \mathrm{~nm}$ despite the size of the hollow spheres. Due to the nanosized hollow sphere and thin shell thickness, $\mathrm{SnO}_{2}$ hollow spheres show excellent electrochemical performance. The smallest hollow sphere of $\mathrm{SnO}_{2}(25 \mathrm{~nm})$ exhibited a high reversible capacity of $750 \mathrm{~mA} \mathrm{~h} \mathrm{~g}{ }^{-1}$ as well as good rate performance, i.e., $700 \mathrm{~mA} \mathrm{~h} \mathrm{~g}{ }^{-1}$ at $0.2 \mathrm{Ag}^{-1}$ and $530 \mathrm{~mA} \mathrm{~h} \mathrm{~g}^{-1}$ at $0.5 \mathrm{~A} \mathrm{~g}^{-1}$ (Fig. 6G). ${ }^{91}$ Hierarchical $\mathrm{SnO}_{2}$ hollow nanostructures can also be assembled by $2 \mathrm{D}$ nanosheets. As shown in Fig. $6 \mathrm{H}$, the hierarchical $\mathrm{SnO}_{2}$ shows high capacities and excellent cycle performance as an anode material for LIBs. The improved electrochemical properties could be ascribed to the large surface area, enhanced structure stability, and short diffusion length for both lithium ions and electrons. ${ }^{211}$

\section{Composites of $\mathrm{SnO}_{2}$ and carbonaceous materials}

\section{1 $\mathrm{SnO}_{2}$ with carbon nanotubes (CNTs)}

Nanocomposites of $\mathrm{SnO}_{2}$ and CNTs reportedly exhibit improved lithium storage capacities compared to pure $\mathrm{SnO}_{2}$ materials. ${ }^{212}$ This can be attributed to the flexible nature and superior conductivity of the CNTs, which alleviates the internal stress caused during the charge/discharge process ${ }^{213-215}$ and enhances the electron transportation. With increased conductivity and surface area, such nanocomposites show enhanced lithium storage capability. ${ }^{216,217}$

Wen et al. reported an in situ synthesis of mesoporous $\mathrm{SnO}_{2}$ on the surface of multi-walled CNTs (MWCNTs) through a hydrothermal method utilizing CTAB as the structuredirecting agent. The MWCNTs/SnO ${ }_{2}$ hybrid electrodes showed great electrochemical performance and cycling stability. This can be attributed to the synergistic effects of the unique combination of properties including their one-dimensional hollow structure, high-strength with flexibility, excellent electric conductivity, and large surface area, which helped alleviate the effect of volume expansion, shorten the distance of $\mathrm{Li}^{+}$ diffusion, and contribute to the transmission of electrons. ${ }^{100,218-221}$

In another hydrothermal system, Du et al. synthesized $\mathrm{SnO}_{2} /$ MWCNT composites by a simple solvothermal method and subsequent heat treatment at $360{ }^{\circ} \mathrm{C}$ with $\mathrm{SnCl}_{2}$ and CNTs as reactants. The distribution of $\mathrm{SnO}_{2}$ nanocrystals can be controlled by changing the molar ratio of $\mathrm{Sn}^{2+}$ and CNTs in the precursor. For $\mathrm{SnO}_{2} / \mathrm{MWCNTs}$ composites prepared with a molar ratio of $\mathrm{Sn}: \mathrm{C}=0.3: 1$, a uniform layer of $\mathrm{SnO}_{2}$ nanocrystals, with a crystal size of about $5 \mathrm{~nm}$, was deposited on the surface of the MWCNTs (Fig. 7A). ${ }^{222}$ These composites showed 

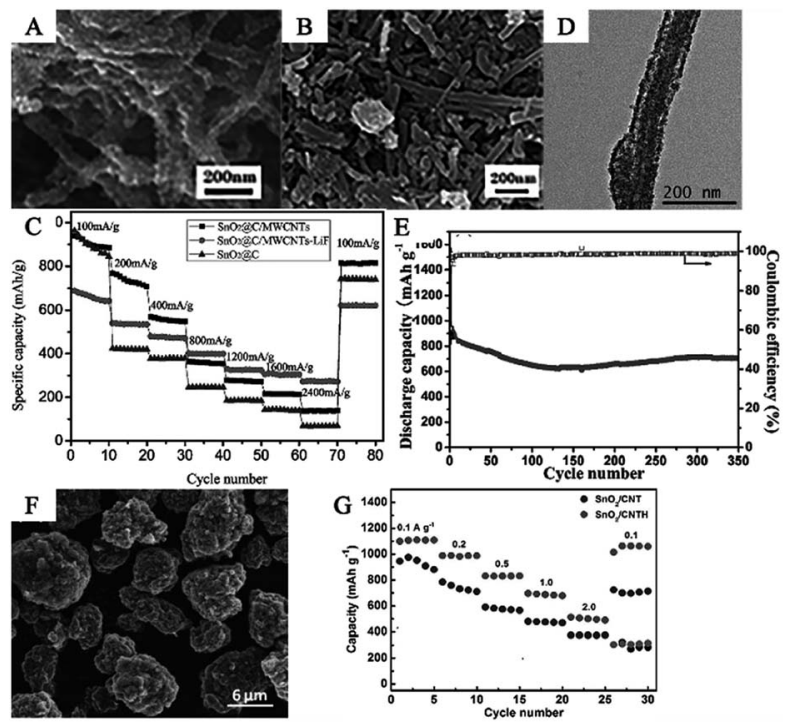

Fig. 7 (A) FESEM image of $\mathrm{SnO}_{2} / \mathrm{CNT}$ composites prepared with MSn : $C=0.3: 1$ (adapted with permission from ref. 221 copyright 2009 Elsevier). (B) SEM image, and (C) rate performance of $\mathrm{SnO}_{2} \mathrm{QC} /$ MWCNTs-LiF (adapted with permission from ref. 224 copyright 2019 Elsevier). (D) TEM image and (E) cycling performance of CNT@void@ $\mathrm{SnO}_{2}$ (aC composite (adapted the permission from ref. 225 copyright 2015 Elsevier). (F) SEM image, and (G) rate performance of $\mathrm{SnO}_{2} / \mathrm{CNTH}$ composites (adapted with permission from ref. 226 copyright 2019 American Chemical Society).

very stable cycling retention, of up to 100 cycles, because of nanosized materials and the introduction of CNTs. ${ }^{201,223} \mathrm{Jin}$ et al. prepared $\mathrm{SnO}_{2} / \mathrm{MWCNTs}$ electrodes via a hydrothermal method at $150{ }^{\circ} \mathrm{C}$ for $24 \mathrm{~h}$. The $\mathrm{SnO}_{2}$ nanoparticles with diameters of less than $3 \mathrm{~nm}$ were uniformly loaded onto the surface of MWCNTs. The MWCNT/SnO 2 nanocomposites exhibited a high reversible capacity of $420 \mathrm{~mA} \mathrm{~h} \mathrm{~g}^{-1}$ even after 100 cycles. ${ }^{137,224}$

In order to further improve electrochemical properties of the $\mathrm{SnO}_{2} / \mathrm{CNTs}$ hybrid nanomaterials, many groups have synthesized various $\mathrm{SnO}_{2} / \mathrm{CNTs}$-based anode materials. For example, Liang et al. synthesized $\mathrm{SnO}_{2} @ \mathrm{C} / \mathrm{MWCNTs}$-lithium fluoride (LiF) composite nanomaterials (Fig. 7B). Carbon-coated $\mathrm{SnO}_{2}$ $\left(\mathrm{SnO}_{2} @ \mathrm{C}\right)$ was prepared by a spray drying method, with watersoluble asphalt as the carbon source and MWCNTs as the conductive agent. The conductivity was significantly enhanced, and the extent of volume expansion of the $\mathrm{SnO}_{2}$ was reduced. Compared to $\mathrm{SnO}_{2} / \mathrm{CNTs}$, the presence of LiF enhanced the stability of the SEI film and improved the coulombic efficiency and capacity retention rate of the electrode. After 200 cycles, the $\mathrm{SnO}_{2} @$ C/MWCNTs-LiF anode still maintained $70.1 \%$ of the capacity retention rate and the specific capacity was held at $274 \mathrm{~mA} \mathrm{~h} \mathrm{~g}^{-1}$ at $2400 \mathrm{~mA} \mathrm{~g}^{-1}$, compared with $136 \mathrm{~mA} \mathrm{~h} \mathrm{~g}^{-1}$ for the $\mathrm{SnO}_{2} @ \mathrm{C} / \mathrm{MWCNTs}$ anode (Fig. $7 \mathrm{C}$ )..$^{225}$ Tian et al. fabricated a tube-in-tube nanostructure, denoted as CNT@void@SnO ${ }_{2} @ \mathrm{C}$, by a facile hydrothermal method and subsequent carbonation with polysaccharide as the carbon source, $\mathrm{SiO}_{2}$ as the sacrificial template, and $\mathrm{NH}_{4} \mathrm{~F}$ as the etchant. The CNT@void@SnO $\mathrm{S}_{2} @ \mathrm{C}$ exhibited one-dimensional nanostructures with average diameters of about 100-150 $\mathrm{nm}$ and hollow structures filled with abundant voids (Fig. 7D). Tian et al. interpreted the formation mechanism as follows: (1) the crystallization and deposition of $\mathrm{SnO}_{2}$ could occur prior to the polycondensation of glucose; (2) the formation rate of $\mathrm{SnO}_{2} @$ polysaccharide was faster than the etching rate of $\mathrm{SiO}_{2}$ by $\mathrm{NH}_{4} \mathrm{~F}$ due to the slow etching process of $\mathrm{SiO}_{2}$ by $\mathrm{NH}_{4} \mathrm{~F}$ solution under hydrothermal condition; and (3) the large void-space between the $\mathrm{SnO}_{2}$ @polysaccharide and CNT, formed after the $\mathrm{SiO}_{2}$ coating layer, was etched away completely. The CNT@void@SnO $\mathrm{S}_{2} @ \mathrm{C}$ exhibited good electrochemical properties, delivering a reversible capacity of $702.5 \mathrm{~mA} \mathrm{~h} \mathrm{~g}^{-1}$ at $200 \mathrm{~mA} \mathrm{~g}^{-1}$ even after 350 cycles (Fig. 7E). This indicated that the unique tube-in-tube nanostructure, as well as the one-dimensional void space, which formed between the inner CNT and outer $\mathrm{SnO}_{2} @ \mathrm{C}$ nanotubes, contributed significantly to the electrochemical performance. ${ }^{226}$ Liu et al. synthesized ultrafine $\mathrm{SnO}_{2}(6-7 \mathrm{~nm}) /$ carbon nanotube hairball $\left(\mathrm{SnO}_{2} / \mathrm{CNTH}\right)$ composites with a $3 \mathrm{D}$ hierarchical structure (Fig. 7F), which was prepared by spray drying and a solvothermal method. Fig. 7G shows that $\mathrm{SnO}_{2} / \mathrm{CNTH}$ exhibited superior electrochemical performance and improved the lithium storage capacity compared to conventional $\mathrm{SnO}_{2} /$ CNT. The improved electrochemical performance can be attributed to the increased conductivity and enhanced electrode reactivity due to the 3D hierarchical cross-linked structure. This structure can also address the large volume changes upon cycling. ${ }^{227}$

\section{2 $\mathrm{SnO}_{2}$ with amorphous carbon}

Hydrothermal treatment followed by carbonization is the most common method for synthesizing $\mathrm{SnO}_{2}$ /amorphous carbon nanomaterials. ${ }^{228-230}$ There are mainly two synthesis routes of $\mathrm{SnO}_{2}$ /amorphous carbon; one is to treat $\mathrm{Sn}^{2+}$ or $\mathrm{Sn}^{4+}$ salt with the precursor of carbon, ${ }^{231-236}$ and the other is to deposit a carbon layer on the as-prepared $\mathrm{SnO}_{2}$ nanostructures. ${ }^{237,238}$ Conventional amorphous carbon can be derived from glucose, ${ }^{239,240}$ sucrose ${ }^{241,242}$ and many organic compounds..$^{243}$ The morphology and shapes of the nanostructures can be adjusted by the hydrothermal and annealing conditions.

Various $\mathrm{SnO}_{2} / \mathrm{C}$ nanomaterials have been synthesized in recent years, such as carbon-coated $\mathrm{SnO}_{2} \mathrm{NPs}^{244-247}$ carboncoated $\mathrm{SnO}_{2}$ nanorods, ${ }^{248,249}$ carbon-coated $\mathrm{SnO}_{2}$ nanowires ${ }^{151,217}$ and carbon-coated $\mathrm{SnO}_{2}$ nanotubes. ${ }^{57}$ Different structures and morphologies of $\mathrm{SnO}_{2}$ are known to lead to different electrochemical performance. In 2008, Lou et al. prepared $\mathrm{SnO}_{2} / \mathrm{C}$ composite hollow spheres. The mesoporous $\mathrm{SnO}_{2}$ hollow spheres were embedded in 3D carbon networks (Fig. 8A). The carbon networks act as a physical buffering cushion for the intrinsic large volume change and electronically conducting pathways. Compared to $\mathrm{SnO}_{2}$ hollow spheres and graphite, these $\mathrm{SnO}_{2} /$ carbon hollow spheres were able to deliver a reversible lithium storage capacity of $473 \mathrm{~mA} \mathrm{~h} \mathrm{~g}^{-1}$ after 50 cycles (Fig. 8B). ${ }^{99}$ In 2009, Lou et al. also synthesized a thin layer of carbon-coated $\mathrm{SnO}_{2}$ nano-colloids (Fig. 8C) and coaxial $\mathrm{SnO}_{2} @$ @arbon hollow nanospheres (Fig. 8D) by a simple hydrothermal method followed by carbonization; both 

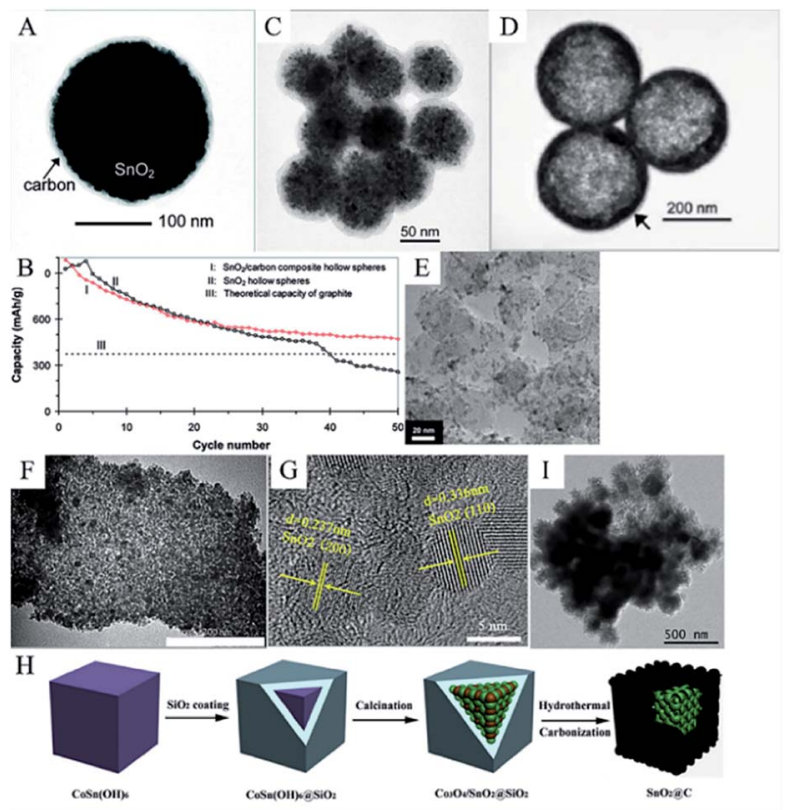

Fig. 8 (A) TEM image, and (B) cycling performance of $\mathrm{SnO}_{2} /$ carbon composites hollow spheres (adapted with permission from ref. 99 copyright 2008 American Chemistry Society). (C) TEM image of carbon-coated $\mathrm{SnO}_{2}$ nanocolloids obtained after carbonization at $550{ }^{\circ} \mathrm{C}$ (adapted with permission from ref. 239 copyright 2009 American Chemical Society). (D) TEM image of $\mathrm{SnO}_{2}$ (acarbon hollow nanospheres (adapted with permission from ref. 240 copyright 2009 Wiley). (E) TEM image of nanosized $\mathrm{SnO}_{2}$ /carbon composites (adapted with permission from ref. 248 copyright 2009 Elsevier). (F) TEM image, and (G) HRETM image of $\mathrm{SnO}_{2} / \mathrm{RHPC}$ composite materials (adapted with permission from ref. 231 copyright 2019 Elsevier). (H) The fabrication schematic of $\mathrm{SnO}_{2}$ (anon-smooth carbon. (I) TEM image of $\mathrm{SnO}_{2}$ quasi-nanocubesanon-smooth carbon (adapted with permission from ref. 255 copyright 2019 Elsevier).

exhibited improved electrochemical performance..$^{57,250}$ Courtel et al. reported an in situ synthesis of $\mathrm{SnO}_{2}$ nanoparticles (5-10 $\mathrm{nm}$ )/carbon composite materials using the polyol method by oxidizing $\mathrm{SnCl}_{2} \cdot 2 \mathrm{H}_{2} \mathrm{O}$ in the presence of a carbon matrix. The TEM image (Fig. 8E) show that the $\mathrm{SnO}_{2}$ nanoparticles were uniformly embedded in the carbon matrix. Based on the nanostructure, the as-obtained composites showed an improved lithium storage capacity of $370 \mathrm{~mA} \mathrm{~h} \mathrm{~g} \mathrm{~g}^{-1}$ at $200 \mathrm{~mA} \mathrm{~g}^{-1}$ and a lower capacity fading compared to commercial $\mathrm{SnO}_{2}(50 \mathrm{~nm}){ }^{251}$

While the morphology and structure of $\mathrm{SnO}_{2}$ influence the electrochemical properties of the $\mathrm{SnO}_{2} / \mathrm{C}$ composites, different carbonaceous materials also influence the performance of the composite. $\mathrm{Xu}$ et al. prepared composites of $\mathrm{SnO}_{2} /$ ordered mesoporous carbon $\left(\mathrm{SnO}_{2} / \mathrm{OMC}\right)$ through a hydrolysis process. OMC, a novel kind of carbon material, has been widely used in LIBs due to its large surface area, high conductivity, and highly porous structure; it promotes the diffusion of lithium ions and electrolyte. The $\mathrm{SnO}_{2} / \mathrm{OMC}$ composites delivered a good cycling performance with a reversible capacity of $395.6 \mathrm{~mA} \mathrm{~h} \mathrm{~g}^{-1}$ for up to 50 cycles. ${ }^{252}$ Shi et al. synthesized $\mathrm{SnO}_{2} /$ rice-husk-based porous carbon composites (RHPC) via a simple melt- impregnation method with a heat treatment route. RHPC can be easily and cheaply obtained by convenient carbonization and activation of rice husk. The TEM images (Fig. 8F and G) show that the $\mathrm{SnO}_{2}$ nanoparticles with the average size of $4 \mathrm{~nm}$ can be loaded on the RHPC matrix. The cycling measurements showed that the discharge capacity of the $\mathrm{RHPC} / \mathrm{SnO}_{2}$ anode at the current density of $100 \mathrm{~mA} \mathrm{~g}{ }^{-1}$, at the $50^{\text {th }}$ cycle, was $550 \mathrm{~mA} \mathrm{~h} \mathrm{~g}^{-1}$, which demonstrated that in contrast to pure $\mathrm{SnO}_{2}$ anodes, the cycling performance of the $\mathrm{RHPC} / \mathrm{SnO}_{2}$ anode was remarkably enhanced by the introduction of the RHPC matrix. It also demonstrates that biomass-sourced carbonaceous materials like RHPC ${ }^{253-255}$ have promising applications in LIBs due to their low cost and porous structure. ${ }^{233}$ Tian et al. fabricated non-smooth carbon-coated $\mathrm{SnO}_{2}$ quasi-nanocubes. Generally, in $\mathrm{SnO}_{2} / \mathrm{C}$ nanocomposites, nanostructured $\mathrm{SnO}_{2}$ is usually coated with smooth carbon, which is easily fabricated from organically sourced carbon via hydrothermal or CVD methods. ${ }^{90,256}$ However, it is believed that $\mathrm{SnO}_{2}$-coated 3D nonsmooth carbon usually shows better lithium storage properties owing to the substantial free space and larger surface area of the 3D structure. ${ }^{257}$ In this work, Tian et al. synthesized the hybrid nanostructures via multiple hydrothermal and calcination methods (Fig. 8H). As shown by the TEM images (Fig. 8I), the porous $\mathrm{SnO}_{2}$ quasi-nanocubes were coated by a carbon layer with a rough surface. The introduction of 3D non-smooth carbon can reduce the transmission length of electrons and $\mathrm{Li}^{+}$and increase the electrochemical reaction sites. Based on such 3D porous structures, the $\mathrm{SnO}_{2} @ \mathrm{C}$ anode displayed extraordinary cycling performance and outstanding rate capability, maintaining a capacity of $1089.5 \mathrm{~mA} \mathrm{~h} \mathrm{~g}^{-1}$ at $200 \mathrm{~mA} \mathrm{~g}^{-1}$,

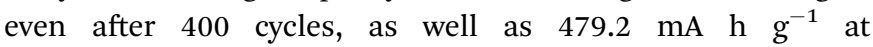
$3000 \mathrm{~mA} \mathrm{~g}^{-1} .^{257}$

It is worth mentioning that even though the amorphous carbon layer can enhance the cycling stability and conductivity of the composites, it has a relatively low lithium storage capacity compared to $\mathrm{SnO}_{2}$. Therefore, the ratio of the carbon layer and the $\mathrm{SnO}_{2}$ nanomaterial determines the capacity and cycle life of the composites.

\section{3 $\mathrm{SnO}_{2} /$ graphene}

As an important 2D carbon material, graphene has quickly gained importance in material science in recent years. Due to its excellent mechanical properties and superior conductivity, graphene has been widely studied in LIBs. ${ }^{258-260}$ Compared to CNTs and amorphous carbon, graphene exhibits higher specific discharge capacity, high surface area, good mechanical properties, and high chemical stability; ${ }^{261-263}$ thus, $\mathrm{SnO}_{2} /$ graphene, as an anode material in LIBs, shows better electrochemical performance. $^{264-268}$

Graphene can be used as a supporting substrate for the synthesis of hierarchical $\mathrm{SnO}_{2}$ nanostructures. For example, Ding et al. fabricated $2 \mathrm{D} \mathrm{SnO}_{2}$ nanosheets grown on a graphene oxide (GO) support via a facile hydrothermal method. $\mathrm{The}_{\mathrm{SnO}_{2}}$ nanosheets were uniformly embedded in the GO support, approximately $100 \mathrm{~nm}$ in length and $5-10 \mathrm{~nm}$ in thickness (Fig. 9A). This unique $\mathrm{SnO}_{2} / \mathrm{GO}$ hybrid structure exhibited 


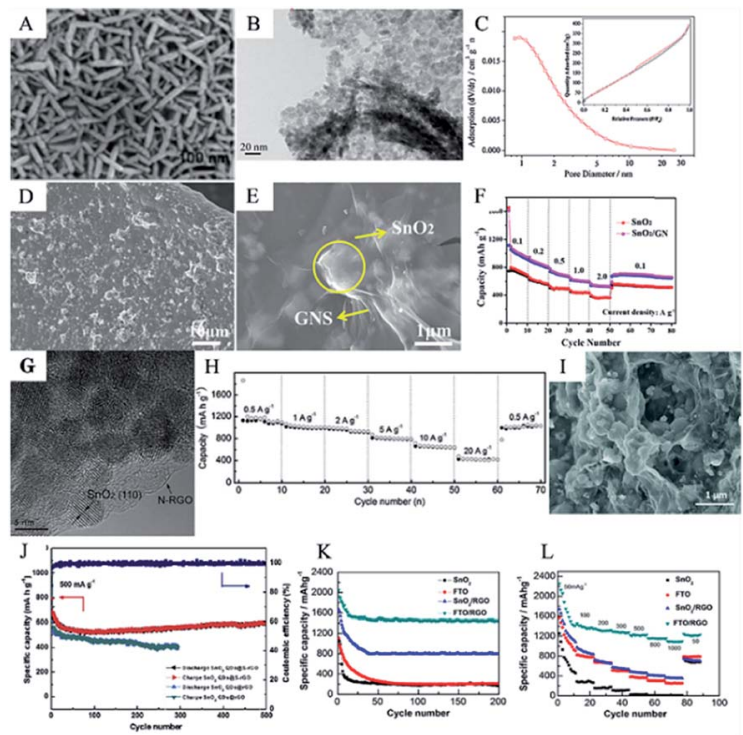

Fig. 9 (A) SEM image of $\mathrm{SnO}_{2}$ nanosheets/graphene (adapted with permission from ref. 170 copyright 2011 Royal Society of Chemistry). (B) TEM image and (C) nitrogen adsorption-desorption isotherms of $\mathrm{SnO}_{2}$ nanoparticles/graphene (adapted with permission from ref. 169 copyright 2017 Elsevier). (D and E) SEM images and (F) rate performance of $\mathrm{SnO}_{2} / \mathrm{GN}$ on $\mathrm{Ni}$ foam (adapted with permission from ref. 267 copyright 2018 Elsevier). (G) HRTEM image and $(\mathrm{H})$ rate performance of $\mathrm{SnO}_{2} \mathrm{NC}(\mathrm{N}-\mathrm{RGO}$ (adapted with permission from ref. 173 copyright 2013 Wiley). (I) SEM images of $\mathrm{SnO}_{2-x} / \mathrm{N}-\mathrm{rGO}$ (adapted with permission from ref. 280 copyright 2018 Royal Society of Chemistry). (J) Cycling stability of $\mathrm{SnO}_{2} \mathrm{QDs}(\mathrm{SS}-\mathrm{rGO}$ (adapted with permission from ref. 277 copyright 2018 Elsevier). (K) Cycling performance and (L) rate performance of $\mathrm{FTO} / \mathrm{rGO}$ (adapted with permission from ref. 109 copyright 2015 American Chemical Society).

enhanced lithium storage properties with high reversible capacities, i.e., an initial discharge capacity of $1666 \mathrm{~mA} \mathrm{~h} \mathrm{~g}^{-1}$, and good cycling performance, i.e., $518 \mathrm{~mA} \mathrm{~h} \mathrm{~g}^{-1}$ after 50 cycles at $400 \mathrm{~mA} \mathrm{~h} \mathrm{~g}{ }^{-1} \cdot{ }^{171}$ Additionally, due to its mechanical properties and electronic conductivity, graphene can serve as the carbon matrix to accommodate the $\mathrm{SnO}_{2}$ nanoparticles. In 2017, Shi et al. investigated a facile microwave-assisted hydrothermal method to synthesize a composite of $\mathrm{SnO}_{2}$ and graphene, which took only $30 \mathrm{~min}$ and did not require any chelating agents. As shown by TEM images (Fig. 9B) and the nitrogen adsorptiondesorption isotherms (Fig. 9C), Shi et al. found that ultra-small $\mathrm{SnO}_{2}$ nanoparticles were well dispersed on the surface of the graphene, with an average particle size of about 3-8 $\mathrm{nm}$. It also showed superior lithium storage capability. The charge/ discharge capacity of this material was 969.4/978.6 $\mathrm{mA} \mathrm{h} \mathrm{g}^{-1}$ after 100 cycles at $200 \mathrm{~mA} \mathrm{~g}^{-1} \cdot{ }^{269}$ Binder-free multilayered $\mathrm{SnO}_{2} /$ graphene on Ni foam was fabricated via a dip-coating method. $\mathrm{SnO}_{2}$ nanoparticles and grapheme were alternatively coated on to the Ni foam to obtain a sandwich-like structure. As shown in SEM images in Fig. 9D and $\mathrm{E}, \mathrm{SnO}_{2}$ nanoparticles were uniformly distributed on the surface of the Ni foam and wrapped tightly in GN. Such a multilayered nanostructure showed superior electrochemical performance due to the following factors: (1) 3D porous Ni foam serves as a conductive network and binder-free current which is beneficial for electron and ion diffusion; (2) the graphene layer improves the conductivity of anode material and buffers the $\mathrm{SnO}_{2}$ volume changes; and (3) the extent of volume change of the $\mathrm{SnO}_{2}$ nanoparticles is lower than that of bulk $\mathrm{SnO}_{2}$. Owing to such porous Ni foam frameworks and sandwich-like structures, the $\mathrm{SnO}_{2}$ /graphene composites exhibited good rate performance and excellent cycling stability. High capacities, i.e., 708 and $609 \mathrm{~mA} \mathrm{~h} \mathrm{~g} \mathrm{~g}^{-1}$ were achieved at current densities 1 and $2 \mathrm{~A} \mathrm{~g}^{-1}$, respectively (Fig. 9F). Furthermore, the $\mathrm{SnO}_{2} / \mathrm{GN}$ electrode delivered a high capacity of $757 \mathrm{~mA} \mathrm{~h} \mathrm{~g}^{-1}$ after 500 cycles at $1 \mathrm{~A} \mathrm{~g}^{-1} \cdot{ }^{174}$

Moreover, it is worth mentioning that atom-doped graphene can also be used as a carbon matrix for $\mathrm{SnO}_{2}$, which effectively enhances the electrochemical performance of the composites. Heteroatoms in graphene can act as anchor sites that prevent aggregation and exfoliation of the $\mathrm{SnO}_{2}$ anchored on graphene; this helps improve the cycling stability of such anode materials. ${ }^{270-274}$ Liu et al. synthesized $\mathrm{SnO}_{2}$ nanoparticles anchored on chlorinated graphene $\left(\mathrm{SnO}_{2} @ \mathrm{rGO}-\mathrm{Cl}\right)$ as binder-free electrodes that exhibit a long cycling life, of up to 400 cycles, with a discharge capacity of $1008 \mathrm{~mA} \mathrm{~h} \mathrm{~g}^{-1}$ via a facile strategy using a one-step heat treatment at low temperature. ${ }^{275}$ Liu et al. found that Cl-doping can enhance the electrical conductivity of graphene and the Cl-Sn bonds can prevent the exfoliation of $\mathrm{SnO}_{2}$ nanoparticles during the charge/discharge process; thus, improving the electrochemical properties of $\mathrm{SnO}_{2}$-based hybrid nanomaterials. $\mathrm{SnO}_{2} /$ nitrogen-doped graphene (N-rGO) was also applied as an anode in LIBs. It is believed that $\mathrm{N}$-doped carbonaceous materials enhance the electronic conductivity and SEI film stability. ${ }^{276-278}$ Zhou et al. fabricated $\mathrm{SnO}_{2} @ \mathrm{~N}-\mathrm{rGO}$ via a hydrazine monohydrate vapor reduction approach for anchoring $\mathrm{SnO}_{2}$ nanocrystals uniformly into N-rGO (Fig. 9G). Due to the bond formed between $\mathrm{SnO}_{2}$ and graphene, and the void pores dispersed in N-rGO, the as-prepared hybrid materials displayed superior mechanical properties and lithium storage capacity. $\mathrm{SnO}_{2} @ \mathrm{~N}-\mathrm{rGO}$ anode showed a reversible charge capacity of $1346 \mathrm{~mA} \mathrm{~h} \mathrm{~g}^{-1}$ after 500 cycles; furthermore, as the current density increased from 0.5 to $1,2,5,10$, and $20 \mathrm{~A} \mathrm{~g}^{-1}$, their discharge capacity varied from 1074 to 994, 915, 782, 631, and $417 \mathrm{~mA} \mathrm{~h} \mathrm{~g}^{-1}$, respectively (Fig. $\left.9 \mathrm{H}\right) .{ }^{279} \mathrm{Wu}$ et al. synthesized the $\mathrm{SnO}_{2-x} / \mathrm{N}-\mathrm{rGO}$ hybrid material through electrostatic adsorption-induced self-assembly together with a thermal reduction process. This treatment induced the generation of the oxygen vacancies on the surface of $\mathrm{SnO}_{2}$ hollow nanospheres; thus, building up a long-range and bi-continuous transfer channel for rapid electron and ion transport. Meanwhile, $\mathrm{SnO}_{2-x}$ hollow spheres are well-wrapped by graphene sheets; thus, enhancing the conductivity of the anode material (Fig. 9I). Due to these structural advantages, the as-obtained $\mathrm{SnO}_{2-x} / \mathrm{N}$ rGO electrode exhibited excellent robust cycling stability, i.e., about $912 \mathrm{~mA} \mathrm{~h} \mathrm{~g}{ }^{-1}$ after 500 cycles at $0.5 \mathrm{~A} \mathrm{~g}^{-1}$ and $652 \mathrm{~mA} \mathrm{~h} \mathrm{~g}{ }^{-1}$ after 200 cycles at $1 \mathrm{~A} \mathrm{~g}^{-1}$, and superior rate capability, i.e., $309 \mathrm{~mA} \mathrm{~h} \mathrm{~g}{ }^{-1}$ at $10 \mathrm{~A} \mathrm{~g}^{-1} \cdot{ }^{280}$ Sulfur-doped graphene (S-rGO) also proved to be a feasible anode material for LIBs. ${ }^{281}$ Compared to the $\mathrm{C}$ atom, the $\mathrm{S}$ atom has a larger volume and lower electronegativity, which is beneficial for the diffusion of $\mathrm{Li}^{+}$and electrons. For instance, Wu et al. successfully loaded 
$\mathrm{SnO}_{2}$ quantum dots (QDs) on sulfur-doped reduced graphene oxide (S-rGO), and it exhibited excellent lithium storage with a high specific capacity of $897 \mathrm{~mA} \mathrm{~h} \mathrm{~g}^{-1}$ and a long cycling stability with $88 \%$ capacity retention after 500 cycles (Fig. 9J). ${ }^{282}$ The abovementioned results demonstrate that heteroatoms can tailor the electronic structure of carbon and create topological defects in the carbon lattice. ${ }^{281,283}$

Apart from doped-graphene, atom-doped $\mathrm{SnO}_{2}$, such as fluorine-doped tin oxide ${ }^{138}$ and antimony-doped tin oxide ${ }^{122}$ can also be used with pristine graphene as an anode material. ${ }^{\mathbf{2 8 4 - 2 8 7}}$ For example, Xu et al. has successfully fabricated composites of fluorine-doped tin oxide (FTO) and rGO from a colloidal solution containing FTO nanocrystals and rGO by a hydrothermal treatment; the FTO nanocrystals were tightly embedded in the RGO nanosheets. As an anode material, the FTO/RGO composite showed high structural stability during the lithiation and delithiation processes. The conductive FTO nanocrystals help form stable and thin SEI films. Moreover, the FTO/ RGO composite retains a discharge capacity as high as $1439 \mathrm{~mA} \mathrm{~h} \mathrm{~g}^{-1}$ after 200 cycles at $100 \mathrm{~mA} \mathrm{~g}^{-1}$ (Fig. 9J), and $1148 \mathrm{~mA} \mathrm{~h} \mathrm{~g}^{-1}$ at $1000 \mathrm{~mA} \mathrm{~g}^{-1}$ (Fig. 9K). ${ }^{109}$

\subsection{Complex $\mathrm{SnO}_{2} / \mathrm{C}$ nanostructure}

Compared to $1 \mathrm{D}$ or $2 \mathrm{D}$ carbonaceous materials, complex $3 \mathrm{D}$ carbonaceous matrices usually show better electrochemical properties due to their high specific surface area and porous structure, which is beneficial in suppressing volume changes. ${ }^{288}$ In recent years, various $\mathrm{SnO}_{2} / \mathrm{C}$ complex hybrid nanomaterials have been reported, such as the combination of CNTs and amorphous carbon, ${ }^{288}$ and CNTs and graphene. ${ }^{283,289,290}$ These complex hierarchical $\mathrm{SnO}_{2} / \mathrm{C}$ nanostructures often show superior electrochemical properties, making them an important research subject.

A sandwich structure with carbon nanofiber, $\mathrm{SnO}_{2}$, and nanofiber bundle for carbon-coating (C@SnO $\mathrm{S}_{2}$ (C) has been fabricated by using collagen fiber (CF), which is a typical fibrous protein extracted from cattle skin and is used as a bio-template as well as the carbon source. FESEM image (Fig. 10A) and TEM image (Fig. 10B) show that the average diameter of the $\mathrm{SnO}_{2}$ nanofiber bundle was about 5-10 $\mu \mathrm{m}$ and a layer of $\mathrm{SnO}_{2}$ was sandwiched between the carbon nanofiber and the carbon coating layer. Such hierarchical architectures of the $\mathrm{C} @ \mathrm{SnO}_{2} @ \mathrm{C}$ nanofiber bundle guaranteed a good balance between electron transport and $\mathrm{Li}^{+}$diffusion kinetics. Thus, efficient ambipolar diffusion and reduced volume changes of $\mathrm{SnO}_{2}$ were obtained to ensure structural integrity with high cycling stability. ${ }^{\mathbf{1 6 2}}$

A porous 3D core-shell structured CNT@SnO ${ }_{2}$ composite, with a graphene coating ( $\left.\mathrm{CNT} @ \mathrm{SnO}_{2} @ \mathrm{G}\right)$, has been synthesized via a two-step hydrothermal method. The first step consists of the synthesis of $\mathrm{CNT}_{\mathrm{SnO}}$, and then, CNT@SnO $\mathrm{CNG}_{2}$ is formed in the subsequent step. FESEM image (Fig. 10C) and TEM image (Fig. 10D) show that CNT@ $\mathrm{SnO}_{2}$ (about 20-40 nm in width) particles was distributed across the graphene sheets and was encased in the graphene coating, which suppressed the formation of SEI layers on the surface of the CNT@SnO $\mathrm{SnG}_{2}$ (G.

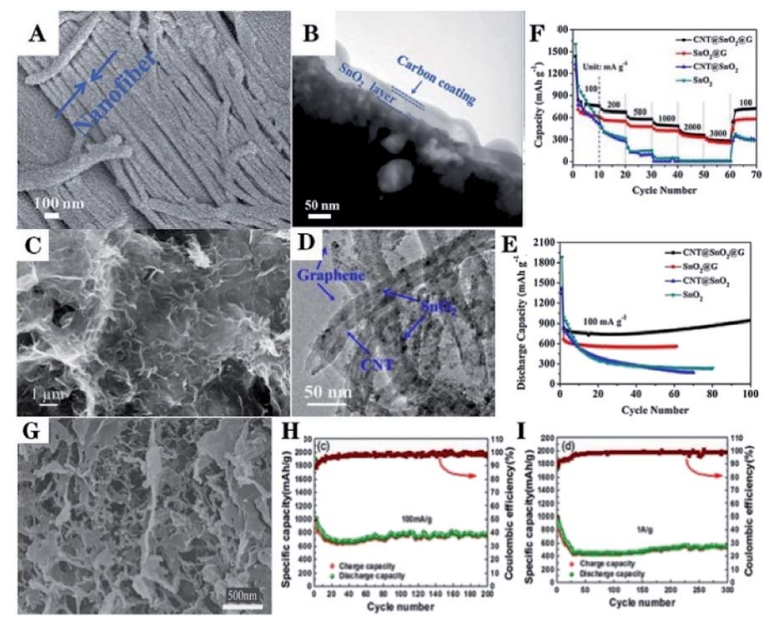

Fig. 10 (A) FESEM image, and (B) TEM image of $\mathrm{CaSnO}_{2}$ aC nanofiber bundle (adapted with permission from ref. 162 copyright 2016 Royal Society of Chemistry). (C) FESEM image, (D) TEM image, (E) cycling performance, and (F) rate performance of $\mathrm{CNT}_{\mathrm{aSnO}} \mathrm{QG}$ (adapted with permission from ref. 263 copyright 2017 Elsevier). (G) SEM image, (H) cycling performance, and (I) rate performance of $\mathrm{SnO}_{2}$ (aG-SWCNT materials (adapted with permission from ref. 289 copyright 2017 American Chemical Society).

The as-prepared $\mathrm{CNT}_{\mathrm{SnO}} @ \mathrm{SnG}_{2}$ electrode exhibited outstanding lithium storage capability, including a large specific capacity, remarkable cycling stability, and excellent rate capability (Fig. 10E and F). ${ }^{265}$

$\mathrm{SnO}_{2}$ nanoparticles anchored on an aerogel based on 3D graphene-single walled carbon nanotube ( $\left.\mathrm{SnO}_{2} @ \mathrm{G}-\mathrm{SWCNT}\right)$, as shown in Fig. 10G, has been fabricated by a hydrothermal selfassembly process. ${ }^{291}$ The 3D G-SWCNT matrix provides a flexible conductive matrix and a more porous network to support $\mathrm{SnO}_{2}$. This is beneficial for facilitating electronic and ionic transportation and mitigating the volume changes of the $\mathrm{SnO}_{2}$ during lithiation/delithiation; thus, leading to enhanced electrochemical performance of the $\mathrm{SnO}_{2}$ anodes for LIBs. The discharge capacity remained $758 \mathrm{~mA} \mathrm{~h} \mathrm{~g}^{-1}$ at $100 \mathrm{~mA} \mathrm{~g}^{-1}$ after 200 cycles (Fig. 10H) and $537 \mathrm{~mA} \mathrm{~h} \mathrm{~g}^{-1}$ at $1 \mathrm{~A} \mathrm{~g}^{-1}$ after 300 cycles (Fig. 10I). ${ }^{291}$

\section{4. $\mathrm{SnO}_{2} / \mathrm{TMOs} / \mathrm{C}$}

The composites of $\mathrm{SnO}_{2}$ and transition metal oxides (TMOs) have been considered as promising anode materials for LIBs. ${ }^{292-294}$ By the introduction of metal oxides, the reversible decomposition of $\mathrm{Li}_{2} \mathrm{O}$ can be increased because TMOs can convert extra $\mathrm{Li}_{2} \mathrm{O}$ into $\mathrm{Li}^{+} ;^{295-297}$ thus, enhancing their cycling stability, rate performance, and rate capability. However, the electrochemical performance of $\mathrm{SnO}_{2}$ /TMOs is unsatisfactory because of low conductivity and large volume expansion, leading to poor cycling stability. ${ }^{\mathbf{1 3 6}}$ In order to overcome these problems, much work has been focused on the fabrication of $\mathrm{SnO}_{2} /$ TMOs/C materials in recent years. Supported and coated by carbonaceous material and TMOs, the structural stability and conductivity of $\mathrm{SnO}_{2}$ can be significantly improved. This 
section will cover synthesis methods, morphology, and electrochemical performance of $\mathrm{SnO}_{2} / \mathrm{TMOs} / \mathrm{C} .{ }^{298-302}$

\section{$4.1 \mathrm{SnO}_{2} / \mathrm{Fe}_{2} \mathrm{O}_{3} / \mathrm{C}$}

$\mathrm{Fe}_{2} \mathrm{O}_{3}$ has been considered as another promising anode material for LIBs due to its large theoretical capacity $\left(1007 \mathrm{~mA} \mathrm{~h} \mathrm{~g}^{-1}\right)$ and low cost. ${ }^{303,304}$ However, the short carrier diffusion length inhibits lithiation/delithiation processes. It has been reported that $\mathrm{SnO}_{2} / \mathrm{Fe}_{2} \mathrm{O}_{3}$ showed an improvement in photocatalysis, energy storage, and gas sensing. ${ }^{303,305-307}$ Furthermore, the $\mathrm{SnO}_{2} /$ $\mathrm{Fe}_{2} \mathrm{O}_{3} / \mathrm{C}$ electrode showed better lithium storage capability. ${ }^{308}$ In this composite, $\mathrm{SnO}_{2}$ possesses a high intrinsic conductivity and a shortened charge diffusion distance, while $\mathrm{Fe}_{2} \mathrm{O}_{3}$ facilitates the reversible decomposition of $\mathrm{Li}_{2} \mathrm{O}$ and prevents $\mathrm{Sn}$ aggregation during charging and discharging. ${ }^{309}$

In 2014, Wu et al. proposed a facile hydrothermal method to synthesize a ternary phased $\mathrm{SnO}_{2} / \mathrm{Fe}_{2} \mathrm{O}_{3} / \mathrm{SWCNTs}$ composite. As shown in Fig. 11A, the composites of $\mathrm{SnO}_{2}$ and $\mathrm{Fe}_{2} \mathrm{O}_{3}$ nanoparticles were well distributed and firmly anchored on to SWCNTs, which serve as a buffer and conductive matrix. Nanosized $\mathrm{Fe}_{2} \mathrm{O}_{3} / \mathrm{SnO}_{2}$ composites can suppress the effect of volume changes and particle agglomeration. The $\mathrm{SnO}_{2} / \mathrm{Fe}_{2} \mathrm{O}_{3} /$ SWCNTs electrode showed a high reversible capacity, superior cycle performance, and high rate capability. It delivered a capacity of $692 \mathrm{~mA} \mathrm{~h} \mathrm{~g}^{-1}$ at $200 \mathrm{~mA} \mathrm{~g}^{-1}$ after 50 cycles. Even at a rate as high as $2000 \mathrm{~mA} \mathrm{~g}^{-1}$, this composite could still maintain its capacity at $656 \mathrm{~mA} \mathrm{~h} \mathrm{~g}^{-1}$ (Fig. 11B). ${ }^{310}$

The growth of $\mathrm{SnO}_{2}$ on $\mathrm{Fe}_{2} \mathrm{O}_{3}$ and subsequent carbon coating on $\mathrm{SnO}_{2} / \mathrm{Fe}_{2} \mathrm{O}_{3}$ is another common synthesis route for $\mathrm{SnO}_{2} /$ $\mathrm{Fe}_{2} \mathrm{O}_{3} /$ C. Du et al. synthesized $\gamma-\mathrm{Fe}_{2} \mathrm{O}_{3} @ \mathrm{SnO}_{2} @ \mathrm{C}$ porous coreshell nanorods. They first formed $\mathrm{FeOOH}$ nanorods via a hydrothermal process, which served as a template for the subsequent $\mathrm{SnO}_{2}$ deposition process in another hydrothermal system. After the deposition of $\mathrm{SnO}_{2}$ on the FeOOH nanorods, the as-synthesized FeOOH@SnO ${ }_{2}$ nanorods were coated with

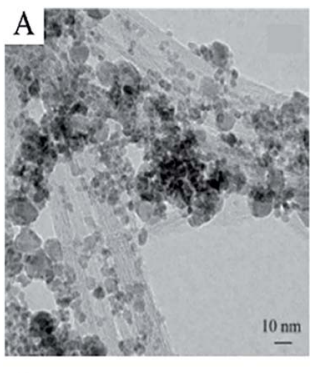

$\mathrm{C}$

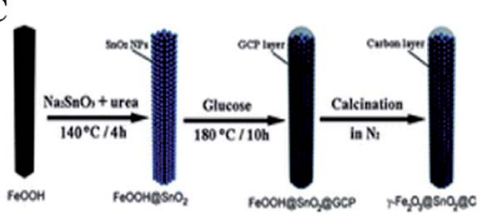

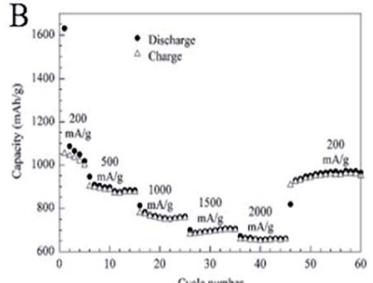

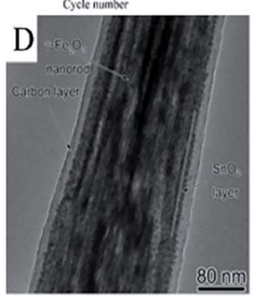

Fig. 11 (A) TEM image, and (B) rate performance of $\mathrm{SnO}_{2} / \mathrm{Fe}_{2} \mathrm{O}_{3} /$ SWCNTs (adapted with permission from ref. 308 copyright 2014 Elsevier). (C) TEM images, and (D) schematic illustration of the synthesis of $\gamma-\mathrm{Fe}_{2} \mathrm{O}_{3} @ \mathrm{CSnO}_{2} \mathrm{aC}$ core-shell nanorods (adapted with permission from ref. 115 copyright 2013 Royal Society of Chemistry). a carbon layer via another hydrothermal process and carbonized under $\mathrm{N}_{2}$ at $500{ }^{\circ} \mathrm{C}$ for $2 \mathrm{~h}$ (Fig. 11C). The TEM image (Fig. 11D) shows that $\mathrm{SnO}_{2}$ can successfully grow on the $\mathrm{Fe}_{2} \mathrm{O}_{3}$ nanostructure with well-defined interfaces. The thickness of the $\mathrm{SnO}_{2}$ layer is $5-10 \mathrm{~nm}$, which is composed of $\mathrm{SnO}_{2}$ nanoparticles with a diameter of about $3-5 \mathrm{~nm}$, and the core nanorod is highly porous. Such a porous core-shell hybrid nanorodbased electrode showed good cycling and rate performance due to the improvement of conductivity and structural stability by the introduction of carbon and $\mathrm{Fe}_{2} \mathrm{O}_{3} \cdot{ }^{115}$

\section{$4.2 \mathrm{SnO}_{2} / \mathrm{Co}_{3} \mathrm{O}_{4} / \mathrm{C}$}

Many studies have concentrated on improving electrochemical properties of $\mathrm{SnO}_{2}$ and $\mathrm{Co}_{3} \mathrm{O}_{4}$ by designing and synthesizing unique nanostructures. Like most transition metals, the presence of Co can improve the reversibility of the reduction reaction of $\mathrm{Li}_{2} \mathrm{O}$ and further enhance the reversible capacity. ${ }^{311-315} \mathrm{As}$ shown in Fig. 12A, $\mathrm{Co}_{3} \mathrm{O}_{4} @ \mathrm{SnO}_{2} @ \mathrm{C}$ core-shell nanorods have been synthesized via a hydrothermal method followed by carbonization. Fig. 12B and $\mathrm{C}$ show that $\mathrm{SnO}_{2}$ nanoparticles uniformly coated the surface of $\mathrm{Co}_{3} \mathrm{O}_{4}$ nanorods and that the coating was smooth and uniform, with a thickness of 5-10 nm. Such materials exhibited improved cycling performance and higher specific capability as an anode material for LIBs ( $860 \mathrm{~mA} \mathrm{~h} \mathrm{~g}^{-1}$ after 50 cycles at $0.2 \mathrm{~A} \mathrm{~g}^{-1}$ ). This result demonstrated that the combination of $\mathrm{SnO}_{2}$ and $\mathrm{Co}_{3} \mathrm{O}_{4}$, into an integrated core-shell nanorod structure, exhibited a better and more elegant synergistic effect during the charge/discharge processes.

$\mathrm{SnO}_{2} / \mathrm{Co}_{3} \mathrm{O}_{4} @ \mathrm{~N}$-doped carbon (NC) usually shows better lithium storage properties compared to most $\mathrm{SnO}_{2} / \mathrm{Co}_{3} \mathrm{O}_{4} / \mathrm{C}$ materials. ${ }^{316}$ Wang et al. successfully designed and fabricated $\mathrm{SnO}_{2} / \mathrm{Co}_{3} \mathrm{O}_{4} / \mathrm{NC}$ nanoflakes via a combined strategy of CVD and template synthesis. ${ }^{119,317}$ HRTEM images (Fig. 12D) show that $\mathrm{SnO}_{2} / \mathrm{Co}_{3} \mathrm{O}_{4}$ nanoparticles were uniformly distributed on the $\mathrm{NC}$ nanoflakes. By adjusting the ratio of the precursor and reaction conditions, they found that the $\mathrm{SnO}_{2} / \mathrm{Co}_{3} \mathrm{O}_{4} @ \mathrm{NC}\left(R_{\mathrm{Sn} /}\right.$

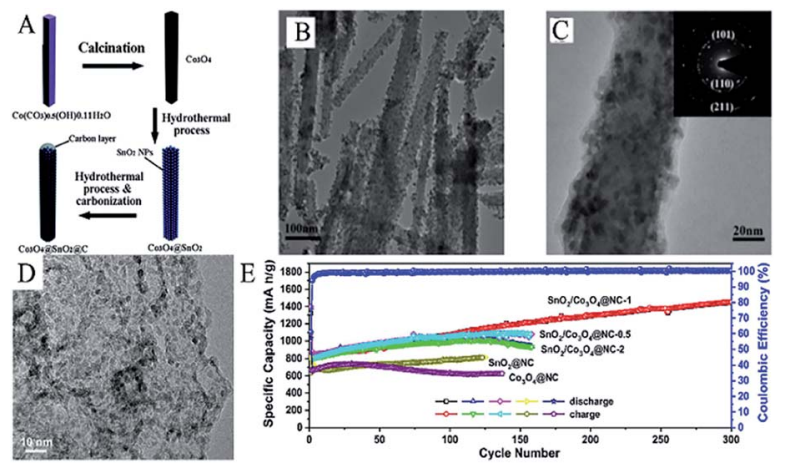

Fig. 12 (A) Schematic illustration of the fabrication of $\mathrm{CO}_{3} \mathrm{O}_{4}$ (a$\mathrm{SnO}_{2} \mathrm{aC}$ core-shell nanorods. (B) TEM image, and (C) HRTEM images of $\mathrm{CO}_{3} \mathrm{O}_{4} \mathrm{aSnO}_{2} \mathrm{aC}$ core-shell nanorods (adapted with permission from ref. 313 copyright 2012 Royal Society of Chemistry). (D) HRTEM image and, (E) cycling performance of $\mathrm{SnO}_{2} / \mathrm{CO}_{3} \mathrm{O}_{4}$ (aNC-1 nanoflakes (adapted with permission from ref. 119 copyright 2019 Elsevier). 
Co $=1: 1)$ nanoflakes-based electrode demonstrated excellent lithium storage capability, i.e., a discharge capacity of $1450.3 \mathrm{~mA} \mathrm{~h} \mathrm{~g}^{-1}$ after 300 cycles at $200 \mathrm{~mA} \mathrm{~h} \mathrm{~g}^{-1}$ (Fig. 12E). The superior lithium storage of such materials may result from the synergistic effect between the combination of $\mathrm{SnO}_{2}$ and $\mathrm{Co}_{3} \mathrm{O}_{4}$ and better conductivity caused by the $\mathrm{N}$-doped carbon matrix. ${ }^{119}$

Therefore, in $\mathrm{SnO}_{2} / \mathrm{Co}_{3} \mathrm{O}_{4} / \mathrm{C}$ composites, $\mathrm{SnO}_{2}$ and $\mathrm{Co}_{3} \mathrm{O}_{4}$ display a synergistic enhancement effect. It can provide additional active sites for lithium storage and shorten the lithium diffusion distance. Additionally, the carbon layer can greatly improve the electrode conductivity and restrain volume changes during the lithiation/delithiation processes.

\section{3 $\mathrm{SnO}_{2} / \mathrm{TiO}_{2} / \mathrm{C}$}

$\mathrm{SnO}_{2}$, as one of the most extensively investigated anode material, which offers a high specific capacity. However, poor cycling stability, due to large volume expansion and subsequent pulverization during $\mathrm{Li}^{+}$insertion/extraction processes, greatly restricts its application as an anode material. ${ }^{130,318-320}$ In contrast, $\mathrm{TiO}_{2}$ exhibits negligible volume change (less than 4\%) and stable electrochemical properties, but its application is limited due to its low specific capacity. ${ }^{321-325}$ Furthermore, $\mathrm{SnO}_{2}$ and $\mathrm{TiO}_{2}$ have complementary characteristics in LIBs, i.e., $\mathrm{Sn}^{4+}$ and $\mathrm{Ti}^{4+}$ possess similar radii and the lattice matching of $\mathrm{SnO}_{2}$ and $\mathrm{TiO}_{2}$ is good. ${ }^{326-328}$ Considering the facts mentioned above, in order to promote cycling stability of $\mathrm{SnO}_{2}$, various $\mathrm{SnO}_{2} / \mathrm{TiO}_{2}$ based hybrid materials have been synthesized. ${ }^{329-334}$

Mesoporous $\mathrm{SnO}_{2} @ \mathrm{C} @ \mathrm{TiO}_{2}$ nanochains have been synthesized by first fabricating $\mathrm{SnO}_{2}$ @C core-shell nanochains via a hydrothermal method and subsequent continuous mechanical stirring of the solution of $\mathrm{SnO}_{2} @ \mathrm{C}$ and tetrabutyl titanate $\left(\mathrm{C}_{16} \mathrm{H}_{36} \mathrm{O}_{4} \mathrm{Ti}\right)$. It is noticeable that the $\mathrm{SnO}_{2}$ core is composed of $\mathrm{SnO}_{2}$ nanoparticles with a diameter of 2-6 $\mathrm{nm}$ and is coated by a thin carbon layer (2-6 nm) as well as a $\mathrm{TiO}_{2}$ layer (about $8 \mathrm{~nm}$ ) (Fig. 13A). In this 3D hierarchical structure, the carbon layer and the $\mathrm{TiO}_{2}$ layer can effectively improve cycling stability and discharge capacity, i.e., the initial discharge capacity of

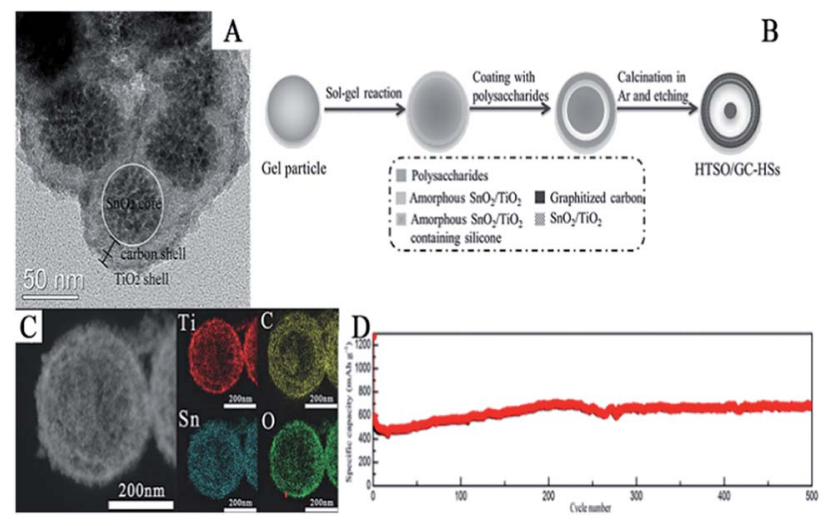

Fig. 13 (A) TEM images of $\mathrm{SnO}_{2}\left(\mathrm{aCaTiO}_{2}\right.$ nanochains (adapted with permission from ref. 296 copyright 2015 Elsevier). (B) Schematic illustration of the synthesis, (C) STEM image, and (D) cycling performance of HTSO/GC-HSs (adapted with permission from ref. 299 copyright 2017 Wiley).
$807 \mathrm{~mA} \mathrm{~h} \mathrm{~g}{ }^{-1}$ and $369 \mathrm{~mA} \mathrm{~h} \mathrm{~g}{ }^{-1}$ after 100 cycles at $100 \mathrm{~mA} \mathrm{~h} \mathrm{~g}{ }^{-1} \cdot{ }^{298}$

Xie et al. reported the synthesis of hierarchical $\mathrm{TiO}_{2} / \mathrm{SnO}_{2}$ hollow spheres coated with graphitized carbon (HTSO/GC-HSs) by a multi-step approach. As shown in Fig. 13B, titanate-silicone gel particles were first reacted with $\mathrm{SnCl}_{2}$ via a sol-gel process to obtain core-shell hybrid structures, which were further coated with a polysaccharide via a hydrothermal process and subsequent carbonization in Ar atmosphere. As shown in Fig. 13C, the as-prepared mesoporous HTSO/GC-HSs had a yolk-shell structure and elements $\mathrm{Sn}, \mathrm{Ti}, \mathrm{O}$ and $\mathrm{C}$ were found to be uniformly distributed in this hierarchical hollow nanostructure. Additionally, they also found that due to the uniform distribution of $\mathrm{SnO}_{2}, \mathrm{TiO}_{2}$, and the carbon layer, a solid solution was formed which could effectively suppress the effect of volume changes during the charge/discharge process. The specific discharge capacity remained at about $680 \mathrm{~mA} \mathrm{~h} \mathrm{~g}^{-1}$ at $1 \mathrm{~A} \mathrm{~g}^{-1}$ after 500 cycles, which demonstrates the excellent cycling performance of HTSO/GC-HSs at high current densities (Fig. 13D). ${ }^{301}$

$\mathrm{SnO}_{2} / \mathrm{TiO}_{2} / \mathrm{C}$ combines the high capacity of $\mathrm{SnO}_{2}$ with the long cycle life and high rate capability of $\mathrm{TiO}_{2} \cdot{ }^{335,336}$ Furthermore, carbonaceous materials can inhibit agglomeration and pulverization of $\mathrm{SnO}_{2}$ and enhance the conductivity of $\mathrm{TiO}_{2} \cdot{ }^{337,338}$ Therefore, $\mathrm{SnO}_{2} / \mathrm{TiO}_{2} / \mathrm{C}$ present an important area of research for the future.

\section{4 $\mathrm{SnO}_{2} / \mathrm{TMOs} /$ graphene}

In the previous sections, we have discussed the synthesis methods, morphologies, and electrochemical performance of some representative $\mathrm{SnO}_{2} / \mathrm{TMOs} / \mathrm{C}$ anode materials. We classified them into different categories according to metal oxides because different TMOs greatly influence the physical and chemical properties of such complex materials due to different reaction mechanisms. In addition, different carbonaceous materials used in $\mathrm{SnO}_{2} / \mathrm{TMOs} / \mathrm{C}$ also influence the electrode performance in LIBs. Among these complex materials, much work has been focused on the fabrication of $\mathrm{SnO}_{2} / \mathrm{TMOs} /$ graphene materials in recent years. Compared to amorphous carbon and CNTs, graphene shows higher lithium storage capacity. ${ }^{339-342}$ Additionally, graphene, as a supportive matrix and conductive network, displays excellent mechanical properties and electronic conductivity, which is conducive to improvement in cycling stability and rate performance of $\mathrm{SnO}_{2}$. Therefore, effectively combining $\mathrm{SnO}_{2}$, TMOs, and graphene, to synthesize high-performance and practical anode material, has been a popular research subject in recent years. ${ }^{46,275,343-345}$

Wang et al. synthesized a $\mathrm{Fe}_{3} \mathrm{O}_{4} / \mathrm{SnO}_{2} / \mathrm{rGO}$ (FSG) composite via a facile hydrothermal method. SEM images (Fig. 14A) and elemental mapping show that FSG consists of $\mathrm{SnO}_{2}$ and $\mathrm{Fe}_{3} \mathrm{O}_{4}$ nanoparticles with diameters of about 10-100 nm, uniformly distributed on the surface of the rGO. In this composite, rGO served as a conductive and robust matrix to prevent aggregation of $\mathrm{Fe}_{3} \mathrm{O}_{4}$ and $\mathrm{SnO}_{2}$ nanoparticles on rGO. As shown in Fig. 14B, the nanocrystallites of $\mathrm{Fe}_{3} \mathrm{O}_{4}$ and $\mathrm{SnO}_{2}$ tend to link with each other, which is beneficial for suppressing both, i.e., the 

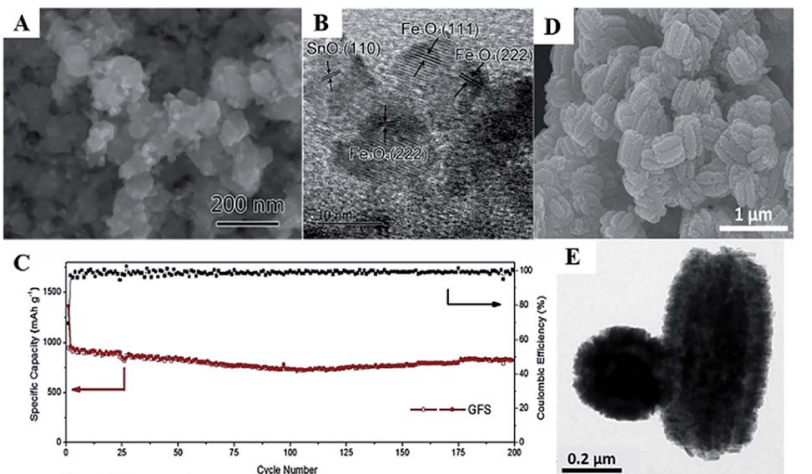

F

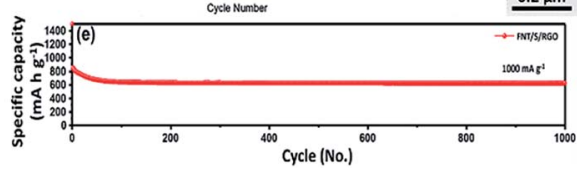

Fig. 14 (A) SEM image, (B) HRTEM image, and (C) cycling performance of FSG (adapted with permission from ref. 132 copyright 2016 Elsevier). (D) SEM image, (E) TEM image from top and side view of CNT/S, and (F) cycling performance of FNT/S/RGO (adapted with permission from ref. 136 copyright 2017 Elsevier).

formation of the SEI film and the volume changes. Such a novel nanostructure can effectively shorten the transport path of $\mathrm{Li}^{+}$ and electrons and helps improve electrolyte penetration. The FSG nanocomposite exhibited a reversible capacity of $947 \mathrm{~mA} \mathrm{~h} \mathrm{~g}^{-1}$ at a current density of $200 \mathrm{~mA} \mathrm{~g}^{-1}$ in the first cycle and maintained a capacity of $831 \mathrm{~mA} \mathrm{~h} \mathrm{~g}^{-1}$ after 200 cycles (Fig. 14C). ${ }^{132}$

Lee et al. have synthesized hollow nanostructured $\alpha-\mathrm{Fe}_{2} \mathrm{O}_{3}$ nanotubes/SnO ${ }_{2} / \mathrm{rGO} \quad(\mathrm{FNT} / \mathrm{S} / \mathrm{G})$ via a microwave-assisted hydrothermal method. As shown in Fig. $14 \mathrm{D}, \mathrm{SnO}_{2}$ nanorods grow on the surface of $\mathrm{FNT}$, and $\mathrm{FNT} / \mathrm{SnO}_{2}$ are uniformly anchored on rGO sheets. The diameter and length (Fig. 14E) of $\mathrm{FNT} / \mathrm{S}$ are about $230 \mathrm{~nm}$ and $660 \mathrm{~nm}$, respectively. Lee et al. also compared the electrochemical performance of FNT, FNT/S, and FNT/S/G. As shown in Fig. 14F, FNT/S/G exhibited the highest discharge capacity under all tested current densities. FNT/S was the second best, demonstrating that the introduction of $\mathrm{SnO}_{2}$ and rGO can effectively enhance the lithium storage capability and cycling stability of the anode material. The specific discharge capacity of $\mathrm{FNT} / \mathrm{S} / \mathrm{RGO}$ remained at $629 \mathrm{~mA} \mathrm{~h} \mathrm{~g}^{-1}$ at $1 \mathrm{~A} \mathrm{~g}^{-1}$ after 1000 cycles. ${ }^{136,346}$

Other $\mathrm{SnO}_{2} / \mathrm{TMOs} /$ graphene composites like $\mathrm{SnO}_{2} / \mathrm{TiO}_{2} /$ $\mathrm{GN},{ }^{338} \mathrm{SnO}_{2} / \mathrm{CuO} / \mathrm{GN}^{347}$ and $\mathrm{SnO}_{2} / \mathrm{In}_{2} \mathrm{O}_{3} / \mathrm{GN}^{348}$ also exhibit improved electrochemical performance. The introduction of TMOs and graphene effectively improve the lithium storage capacity of $\mathrm{SnO}_{2}$. Graphene serves as a supportive and conductive matrix that inhibits agglomeration and pulverization of $\mathrm{SnO}_{2}$ and TMOs during the charge/discharge process.

\section{Other $\mathrm{SnO}_{2}$-based compounds}

$\mathrm{Li}_{4} \mathrm{Ti}_{5} \mathrm{O}_{12}$ (LTO) has been considered as a promising anode material for LIBs due to its excellent cycling stability during lithiation/delithiation. ${ }^{349,350}$ However, like $\mathrm{TiO}_{2}$, LTO possesses a lower theoretical capacity than other anode materials (175 $\mathrm{mA} \mathrm{h} \mathrm{g}^{-1}$ ) and shows poor rate performance. ${ }^{351,352}$ Therefore, in order to improve lithium storage of LTO and cycling performance of $\mathrm{SnO}_{2}$, an effective strategy is to synthesize composites of $\mathrm{SnO}_{2}$ and LTO nanostructures. Ding et al. synthesized hierarchical yolk-shell LTO- $\mathrm{SnO}_{2}$ structures via a two-step hydrothermal method. They first synthesized $\mathrm{SnO}_{2}$ microspheres at $180{ }^{\circ} \mathrm{C}$ for $12 \mathrm{~h}$ in a hydrothermal system and then, coated LTO on the surface of the $\mathrm{SnO}_{2}$ in another hydrothermal system, followed by calcination at $600{ }^{\circ} \mathrm{C}$ for $3 \mathrm{~h}$. SEM images (Fig. 15A) and TEM images (Fig. 15B) clearly show that the yolks are $\mathrm{SnO}_{2}$ microspheres composed of $\mathrm{SnO}_{2}$ nanoparticles, while the shells consist of LTO nanosheets. Hence, this hierarchical coating structure can effectively improve structural stability and suppress the volume changes of $\mathrm{SnO}_{2}$ microspheres; thus, improving the cycling performance and showing high rate capacity. ${ }^{\mathbf{1 4 2}}$

Heteroatom-doped $\mathrm{SnO}_{2}$ reveals better electrochemical performance compared to pure $\mathrm{SnO}_{2}$. The presence of a dopant may favor the reversible formation of $\mathrm{Li}_{2} \mathrm{O}$ and improve the conductivity of $\mathrm{SnO}_{2}$; thus, enhancing the specific capacity of the anode material. ${ }^{353}$ Various heteroatom-doped $\mathrm{SnO}_{2}$ nanomaterials have been synthesized and tested as anode materials in LIBs. ${ }^{354-356}$ For example, Mueller et al. have synthesized carbon-coated Fe-doped $\mathrm{SnO}_{2}$ nanoparticles (Fig. 15C). The discharge capacity of such materials is about $1726 \mathrm{~mA} \mathrm{~h} \mathrm{~g}$ after 10 cycles at $50 \mathrm{~mA} \mathrm{~g}^{-1}$, which is around twice the theoretical capacity of pure $\mathrm{SnO}_{2} \cdot{ }^{353} \mathrm{Zn}$-doped $\mathrm{SnO}_{2}$ hierarchical cube-like nanomaterials were fabricated via hydrothermal method. As shown in Fig. 15D and E, the cube is about $2 \mu \mathrm{m}$ in length and composed of assembled nanorods which are 20$40 \mathrm{~nm}$ in diameter. The discharge capacity of $\mathrm{Zn}$-doped $\mathrm{SnO}_{2}$

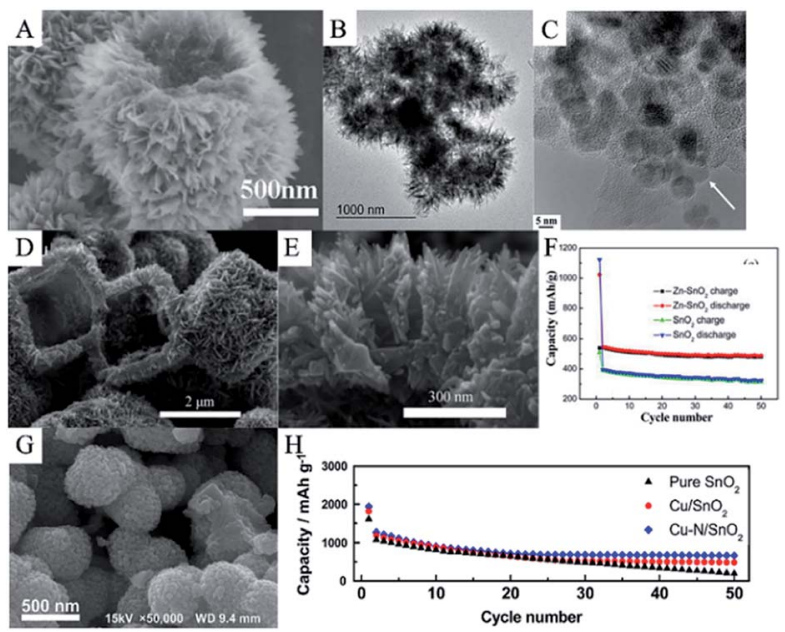

Fig. 15 5(A) SEM image, and (B) TEM image of $\mathrm{LTO}-\mathrm{SnO}_{2}$ composites (adapted with permission from ref. 142 copyright 2018 Elsevier). (C) HRTEM image of carbon-coated $\mathrm{Fe}$-doped $\mathrm{SnO}_{2}$ nanoparticles (adapted with permission from ref. 351 copyright 2015 Elsevier). (D and E) SEM images, and (F) cycling performance of $\mathrm{Zn}$-doped $\mathrm{SnO}_{2}$ nanomaterials (adapted with permission from ref. 355 copyright 2014 Elsevier). (G) SEM image, and (H) cycling performance of $\mathrm{Cu} / \mathrm{N}$-doped $\mathrm{SnO}_{2}$ (adapted with permission from ref. 139 copyright 2014 Elsevier). 
Table 1 Electrochemical property comparison table of some typical $\mathrm{SnO}_{2}$-based anode materials for LIBs

\begin{tabular}{|c|c|c|c|c|c|c|c|}
\hline Materials & Morphology & $\begin{array}{l}\text { Preparation } \\
\text { approach }\end{array}$ & $\begin{array}{l}\text { Voltage } \\
\text { window (V) }\end{array}$ & $\begin{array}{l}\text { Current } \\
\text { density } \\
\left(\mathrm{A} \mathrm{g}^{-1}\right)\end{array}$ & $\begin{array}{l}\text { Cycle } \\
\text { number }\end{array}$ & $\begin{array}{l}\text { Specific } \\
\text { capacity } \\
\left(\mathrm{mA} \mathrm{h} \mathrm{g}^{-1}\right)\end{array}$ & Reference \\
\hline $\mathrm{SnO}_{2}$ nanorods & Diameter of $60 \mathrm{~nm}$ and length of $670 \mathrm{~nm}$ & Hydrothermal & $0.005-2.5$ & 0.078 & 100 & 580 & 154 \\
\hline $\mathrm{SnO}_{2}$ nanotube arrays & $\begin{array}{l}\text { Diameter of } 100-300 \mathrm{~nm} \text { and thickness of } 10- \\
20 \mathrm{~nm}\end{array}$ & $\begin{array}{l}\text { Solvothermal } \\
\text { and annealing }\end{array}$ & $0.005-2$ & 0.078 & 20 & $750-800$ & 64 \\
\hline $\mathrm{SnO}_{2}$ nanowires & Diameter of $6 \mathrm{~nm}$ and length of $>3 \mu \mathrm{m}$ & $\begin{array}{l}\text { Solvothermal } \\
\text { and annealing }\end{array}$ & $0-1.2$ & 0.156 & 50 & 773 & 71 \\
\hline $\mathrm{SnO}_{2}$ nanosheet arrays & Thickness of $20 \mathrm{~nm}$ and length of $500 \mathrm{~nm}$ & Hydrothermal & $0.01-1.2$ & 0.391 & 50 & 674.9 & 79 \\
\hline Hollow $\mathrm{SnO}_{2}$ nanospheres & Size of $100-250 \mathrm{~nm}$ & $\begin{array}{l}\text { Solvothermal } \\
\text { and } \\
\text { hydrothermal }\end{array}$ & $0.01-2$ & 0.391 & 40 & 1140 & 86 \\
\hline $\begin{array}{l}\text { Urchin-like } \mathrm{SnO}_{2} \\
\text { nanospheres }\end{array}$ & Diameter of $300 \mathrm{~nm}$ & Solvothermal & $0.01-3$ & 0.1 & 50 & 719 & 210 \\
\hline $\begin{array}{l}\mathrm{SnO}_{2} \text { nanocrystals/ } \\
\text { MWCNT composites }\end{array}$ & Crystal size of $5 \mathrm{~nm}$ & $\begin{array}{l}\text { Solvothermal } \\
\text { and heat } \\
\text { treatment }\end{array}$ & $0.01-3$ & 0.1 & 100 & 402 & 223 \\
\hline CNT@void@SnO & Tube in tube diameter of $100-150 \mathrm{~nm}$ & Spray drying & $0.01-3$ & 0.2 & 350 & 702.5 & 226 \\
\hline $\begin{array}{l}\mathrm{SnO}_{2} / \mathrm{C} \text { composite hollow } \\
\text { spheres }\end{array}$ & Size of $150-400 \mathrm{~nm}$ & $\begin{array}{l}\text { Hydrothermal } \\
\text { and } \\
\text { carbonation }\end{array}$ & $0-2.5$ & 0.16 & 50 & 473 & 99 \\
\hline $\begin{array}{l}\mathrm{SnO}_{2} \text { nanoparticles/ } \\
\text { carbon composite }\end{array}$ & Nanoparticles of 5-10 nm & Polyol method & $0.005-1.5$ & 0.2 & 100 & 370 & 251 \\
\hline $\mathrm{SnO}_{2}$ nanosheets/GO & Length of $100 \mathrm{~nm}$ and thickness of $5-10 \mathrm{~nm}$ & Hydrothermal & $0.01-1.2$ & 0.4 & 50 & 518 & 171 \\
\hline $\begin{array}{l}\mathrm{SnO}_{2} \text { nanoparticles/ } \\
\text { graphene }\end{array}$ & Particle size of $3-8 \mathrm{~nm}$ & $\begin{array}{l}\text { Microwave- } \\
\text { assisted } \\
\text { hydrothermal }\end{array}$ & $0.01-3$ & 0.2 & 100 & 978.6 & 269 \\
\hline $\mathrm{SnO}_{2} @ \mathrm{rGO}-\mathrm{Cl}$ & Nanoparticle size of $5 \mathrm{~nm}$ & Heat treatment & $0.01-3$ & 0.2 & 400 & 1008 & 275 \\
\hline CNT@SnO ${ }_{2} @ G$ & Width of $20-40 \mathrm{~nm}$ & Hydrothermal & $0.01-3$ & 0.1 & 100 & 947 & 265 \\
\hline $\mathrm{SnO}_{2} @ G-S W C N T$ & $\begin{array}{l}\text { Diameter of 3-5 nm and particle size of 6-8 } \\
\mathrm{nm}\end{array}$ & Hydrothermal & $0.01-3$ & 1 & 300 & 537 & 291 \\
\hline $\begin{array}{l}\mathrm{SnO}_{2}-\mathrm{Fe}_{2} \mathrm{O}_{3} / \mathrm{SWCNTs} \\
\text { nanocomposite }\end{array}$ & Particle size of $10-50 \mathrm{~nm}$ & Hydrothermal & $0.01-3$ & 0.2 & 50 & 692 & 310 \\
\hline $\begin{array}{l}\mathrm{Co}_{3} \mathrm{O}_{4} @ \mathrm{SnO}_{2} @ \mathrm{C} \text { core- } \\
\text { shell nanorods }\end{array}$ & Thickness of $5-10 \mathrm{~nm}$ & Hydrothermal & $0.01-2.5$ & 0.2 & 50 & 860 & 313 \\
\hline $\begin{array}{l}\mathrm{SnO}_{2} @ \mathrm{C} @ \mathrm{TiO}_{2} \\
\text { nanochains }\end{array}$ & $\begin{array}{l}\mathrm{SnO}_{2} \text { for } 2-6 \mathrm{~nm} \text {; thickness of } 2-6 \mathrm{~nm} \text { and } \\
8 \mathrm{~nm} \text { for carbon and } \mathrm{TiO}_{2}\end{array}$ & $\begin{array}{l}\text { Hydrothermal } \\
\text { and } \\
\text { subsequent } \\
\text { mechanical } \\
\text { stirring }\end{array}$ & $0.01-3$ & 0.1 & 100 & 369 & 298 \\
\hline $\begin{array}{l}\mathrm{Fe}_{2} \mathrm{O}_{3} \text { nanotubes } / \mathrm{SnO}_{2} / \\
\text { rGO }\end{array}$ & Diameter of $230 \mathrm{~nm}$ and length of $660 \mathrm{~nm}$ & $\begin{array}{l}\text { Microwave- } \\
\text { assisted } \\
\text { hydrothermal }\end{array}$ & $0.01-3$ & 1 & 1000 & 629 & 136 \\
\hline Yolk-shell LTO-SnO ${ }_{2}$ & Diameter of $1.0-1.5 \mu \mathrm{m}$ & $\begin{array}{l}\text { Hydrothermal } \\
\text { and calcination }\end{array}$ & $0.01-3$ & 0.175 & 200 & 253.2 & 142 \\
\hline $\begin{array}{l}\text { Fe-doped } \mathrm{SnO}_{2} \\
\text { nanoparticles }\end{array}$ & Diameter of $15 \mathrm{~nm}$ & $\begin{array}{l}\text { Hydrothermal } \\
\text { and calcination }\end{array}$ & $0.01-2$ & 0.05 & 10 & 1726 & 351 \\
\hline
\end{tabular}

composites is $488.3 \mathrm{~mA} \mathrm{~h} \mathrm{~g}{ }^{-1}$ after 50 cycles at $10 \mathrm{~mA} \mathrm{~g}^{-1}$ (Fig. 15F). ${ }^{357}$ Wan et al. fabricated $\mathrm{Cu} / \mathrm{N}$-doped $\mathrm{SnO}_{2}$ nanocomposites, as shown in Fig. 15G. They found that with the introduction of $\mathrm{Cu} / \mathrm{N}$, the average diameter of $\mathrm{SnO}_{2}$ became smaller, and the surface became rough, which is beneficial for ion diffusion and suppressing volume expansion. $\mathrm{Cu} / \mathrm{N}$-doped $\mathrm{SnO}_{2}$ electrode materials are known to deliver a discharge capacity of $1939 \mathrm{~mA} \mathrm{~h} \mathrm{~g}^{-1}$ in the first cycle and remain at $664 \mathrm{~mA} \mathrm{~h} \mathrm{~g}^{-1}$ after 50 cycles at $0.1 \mathrm{C}^{139}$

\section{Conclusions}

In this review, we summarized various $\mathrm{SnO}_{2}$-based nanomaterials as anode materials for lithium-ion batteries (Table 1).
By optimizing the structure and composition of the materials, i.e., by synthesizing nanostructured $\mathrm{SnO}_{2}$ and making composites with carbonaceous materials or transition metal oxides (TMOs), the surface area and reaction sites of the anode materials can be effectively increased, improving the electrochemical properties of $\mathrm{SnO}_{2}$-based anode materials. The introduction of carbonaceous materials or TMOs can effectively buffer the internal stresses caused by large volume changes, reduce the irreversible capacity loss, and improve the cycle performance. These aspects lay the foundation for the development and commercialization of high-performance LIBs in the future. Since lithium storage in $\mathrm{SnO}_{2}$ is accompanied by repeatedly inserting and removing lithium ions, volume changes and irreversible capacity loss of $\mathrm{SnO}_{2}$ electrode cannot 
be completely avoided. Significant research on nanosized $\mathrm{SnO}_{2}$ based anode materials has been carried out, and while these materials display superior lithium storage capacity and cycling stability, critical issues like volume expansion and pulverization of $\mathrm{SnO}_{2}$ remain to be solved. Further extensive research is needed before new, non-carbonaceous anode materials, such as $\mathrm{SnO}_{2}$-based nanomaterials, can be commercialized.

\section{Conflicts of interest}

There are no conflicts to declare.

\section{Acknowledgements}

This research was supported by the National Key Research and Development Project (Grant No. 2020YFB1506001), Major Project of Education Department in Sichuan (Grant No. 18ZB0229), Sichuan Province Science and Technology Support Program (Grant No. 18ZDYF2973).

\section{References}

1 J. M. Tarascon and M. Armand, Nature, 2001, 414, 359-367.

2 N. Nitta, F. Wu, J. T. Lee and G. Yushin, Mater. Today, 2015, 18, 252-264.

3 M. V. Reddy, G. V. S. Rao and B. V. R. Chowdari, Chem. Rev., 2013, 113, 5364-5457.

4 V. Etacheri, R. Marom, R. Elazari, G. Salitra and D. Aurbach, Energy Environ. Sci., 2011, 4, 3243-3262.

5 C. Liu, F. Li, L. P. Ma and H. M. Cheng, Adv. Mater., 2010, 22, E28-E62.

6 M.-S. Kim, B. Fang, J. H. Kim, D. Yang, Y. K. Kim, T.-S. Bae and J.-S. Yu, J. Mater. Chem., 2011, 21, 19362-19367.

7 W. Li, L. Zhao, Y. Tian, Y. Gong, X. Huang, Z. Cui and R. Zeng, Electrochim. Acta, 2014, 147, 603-609.

8 J. Cabana, L. Monconduit, D. Larcher and M. Rosa Palacin, Adv. Mater., 2010, 22, E170-E192.

9 A. Magasinski, P. Dixon, B. Hertzberg, A. Kvit, J. Ayala and G. Yushin, Nat. Mater., 2010, 9, 353-358.

10 B. Scrosati, J. Hassoun and Y.-K. Sun, Energy Environ. Sci., 2011, 4, 3287-3295.

11 B. Fang, M.-S. Kim, J. H. Kim, S. Lim and J.-S. Yu, J. Mater. Chem., 2010, 20, 10253-10259.

12 J. B. Goodenough and Y. Kim, Chem. Mater., 2010, 22, 587603.

13 J. Jiang, Y. Li, J. Liu, X. Huang, C. Yuan and X. W. Lou, Adv. Mater., 2012, 24, 5166-5180.

14 K. Chang and W. Chen, ACS Nano, 2011, 5, 4720-4728.

15 Y. Sun, Q. Wu and G. Shi, Energy Environ. Sci., 2011, 4, 11131132.

16 Z.-S. Wu, G. Zhou, L.-C. Yin, W. Ren, F. Li and H.-M. Cheng, Nano Energy, 2012, 1, 107-131.

17 C. Yuan, H. B. Wu, Y. Xie and X. W. Lou, Angew. Chem., Int. Ed., 2014, 53, 1488-1504.

18 N. Liu, Z. Lu, J. Zhao, M. T. McDowell, H.-W. Lee, W. Zhao and Y. Cui, Nat. Nanotechnol., 2014, 9, 187-192.
19 J. B. Goodenough and K.-S. Park, J. Am. Chem. Soc., 2013, 135, 1167-1176.

20 P. G. Bruce, S. A. Freunberger, L. J. Hardwick and J.-M. Tarascon, Nat. Mater., 2012, 11, 19-29.

21 Y. Deng, C. Fang and G. Chen, J. Power Sources, 2016, 304, 81-101.

22 L. Lu, X. Han, J. Li, J. Hua and M. Ouyang, J. Power Sources, 2013, 226, 272-288.

23 J. W. Choi and D. Aurbach, Nat. Rev. Mater., 2016, 1, 16013.

24 W.-B. Hua, X.-D. Guo, Z. Zheng, Y.-J. Wang, B.-H. Zhong, B. Fang, J.-Z. Wang, S.-L. Chou and H. Liu, J. Power Sources, 2015, 275, 200-206.

25 Y. Xing, S. Wang, B. Fang, Y. Feng and S. Zhang, Microporous Mesoporous Mater., 2018, 261, 237-243.

26 W. Hua, Y. Wang, Y. Zhong, G. Wang, B. Zhong, B. Fang, X. Guo, S. Liao and H. Wang, Chin. J. Chem., 2015, 33, 261-267.

27 F. Cheng, Y. Chen, A. Sun, X. Zhou, J. Yang and J. Tang, Ceram. Int., 2019, 45, 13556-13560.

28 J. Jia, X. Hu and Z. Wen, Nano Res., 2018, 11, 1135-1145.

29 T. Wang, H. Li, S. Shi, T. Liu, G. Yang, Y. Chao and F. Yin, Small, 2017, 13, 1604182.

30 G. Xu, L. Zhang, C. Guo, L. Gu, X. Wang, P. Han, K. Zhang, C. Zhang and G. Cui, Electrochim. Acta, 2012, 85, 345-351.

31 H. Xia, M. Lai and L. Lu, J. Mater. Chem., 2010, 20, 68966902.

32 A. L. M. Reddy, M. M. Shaijumon, S. R. Gowda and P. M. Ajayan, Nano Lett., 2009, 9, 1002-1006.

33 J. Zhu and J. He, ACS Appl. Mater. Interfaces, 2012, 4, 17701776.

$34 \mathrm{H} . \mathrm{Xu}, \mathrm{X} . \mathrm{Hu}, \mathrm{H}$. Yang, Y. Sun, C. Hu and Y. Huang, Adv. Energy Mater., 2015, 5, 1401882.

35 B. Sun, Z. Chen, H.-S. Kim, H. Ahn and G. Wang, J. Power Sources, 2011, 196, 3346-3349.

36 D. Kong, J. Luo, Y. Wang, W. Ren, T. Yu, Y. Luo, Y. Yang and C. Cheng, Adv. Funct. Mater., 2014, 24, 3815-3826.

37 S. Zhu, J. Li, X. Deng, C. He, E. Liu, F. He, C. Shi and N. Zhao, Adv. Funct. Mater., 2017, 27, 1605017.

38 H. Wang, L.-F. Cui, Y. Yang, H. S. Casalongue, J. T. Robinson, Y. Liang, Y. Cui and H. Dai, J. Am. Chem. Soc., 2010, 132, 13978-13980.

39 J. Gao, M. A. Lowe and H. D. Abruna, Chem. Mater., 2011, 23, 3223-3227.

40 Z. Cai, L. Xu, M. Yan, C. Han, L. He, K. M. Hercule, C. Niu, Z. Yuan, W. Xu, L. Qu, K. Zhao and L. Mai, Nano Lett., 2015, 15, 738-744.

41 X. Zhu, Y. Zhu, S. Murali, M. D. Stollers and R. S. Ruoff, ACS Nano, 2011, 5, 3333-3338.

42 L. Zhang, H. B. Wu, S. Madhavi, H. H. Hng and X. W. Lou, J. Am. Chem. Soc., 2012, 134, 17388-17391.

$43 \mathrm{X} . \mathrm{Xu}, \mathrm{R}$. Cao, S. Jeong and J. Cho, Nano Lett., 2012, 12, 4988-4991.

44 Z. Wang, D. Luan, S. Madhavi, Y. Hu and X. W. Lou, Energy Environ. Sci., 2012, 5, 5252-5256.

45 M. V. Reddy, T. Yu, C.-H. Sow, Z. X. Shen, C. T. Lim, G. V. S. Rao and B. V. R. Chowdari, Adv. Funct. Mater., 2007, 17, 2792-2799. 
46 G. Zhou, D.-W. Wang, F. Li, L. Zhang, N. Li, Z.-S. Wu, L. Wen, G. Q. Lu and H.-M. Cheng, Chem. Mater., 2010, 22, 5306-5313.

47 W.-M. Zhang, X.-L. Wu, J.-S. Hu, Y.-G. Guo and L.-J. Wan, Adv. Funct. Mater., 2008, 18, 3941-3946.

48 W. Wei, S. Yang, H. Zhou, I. Lieberwirth, X. Feng and K. Muellen, Adv. Mater., 2013, 25, 2909-2914.

49 J. Luo, J. Liu, Z. Zeng, C. F. Ng, L. Ma, H. Zhang, J. Lin, Z. Shen and H. J. Fan, Nano Lett., 2013, 13, 6136-6143.

50 C. He, S. Wu, N. Zhao, C. Shi, E. Liu and J. Li, ACS Nano, 2013, 7, 4459-4469.

51 X. Wang, X.-L. Wu, Y.-G. Guo, Y. Zhong, X. Cao, Y. Ma and J. Yao, Adv. Funct. Mater., 2010, 20, 1680-1686.

52 X. W. Lou, D. Deng, J. Y. Lee, J. Feng and L. A. Archer, Adv. Mater., 2008, 20, 258-262.

53 Y. Li, B. Tan and Y. Wu, Nano Lett., 2008, 8, 265-270.

54 W. Y. Li, L. N. Xu and J. Chen, Adv. Funct. Mater., 2005, 15, 851-857.

55 W. M. Zhang, J. S. Hu, Y. G. Guo, S. F. Zheng, L. S. Zhong, W. G. Song and L. J. Wan, Adv. Mater., 2008, 20, 1160-1165.

56 X. W. Lou, Y. Wang, C. L. Yuan, J. Y. Lee and L. A. Archer, Adv. Mater., 2006, 18, 2325-2329.

57 X. W. Lou, C. M. Li and L. A. Archer, Adv. Mater., 2009, 21, 2536-2539.

58 C. Guo, M. Cao and C. Hu, Inorg. Chem. Commun., 2004, 7, 929-931.

59 B. Liu, J.-G. Zhang and W. Xu, Joule, 2018, 2, 833-845.

60 I. A. Courtney, J. Electrochem. Soc., 1997, 144, 2045.

61 X. Zhou, L.-J. Wan and Y.-G. Guo, Adv. Mater., 2013, 25, 2152-2157.

62 H. Kim, G. O. Park, Y. Kim, S. Muhammad, J. Yoo, M. Balasubramanian, Y.-H. Cho, M.-G. Kim, B. Lee, K. Kang, H. Kim, J. M. Kim and W.-S. Yoon, Chem. Mater., 2014, 26, 6361-6370.

63 M.-S. Park, G.-X. Wang, Y.-M. Kang, D. Wexler, S.-X. Dou and H.-K. Liu, Angew. Chem., Int. Ed., 2007, 46, 750-753.

64 J. Wang, N. Du, H. Zhang, J. Yu and D. Yang, J. Phys. Chem. $C, 2011,115,11302-11305$.

65 Y. Wang, M. Wu, Z. Jiao and J. Y. Lee, Nanotechnology, 2009, 20, 345704 .

66 M. Lai, J. A. Gonzalez Martinez, M. Grätzel and D. J. Riley, J. Mater. Chem., 2006, 16, 2843-2845.

67 N. Du, H. Zhang, B. Chen, X. Ma and D. Yang, Chem. Commun., 2008, 3028-3030.

68 Y. Wang, J. Y. Lee and H. C. Zeng, Chem. Mater., 2005, 17, 3899-3903.

69 S. J. Ding, Z. Y. Wang, S. Madhavi and X. W. Lou, J. Mater. Chem., 2011, 21, 13860-13864.

70 Y. T. Han, X. Wu, Y. L. Ma, L. H. Gong, F. Y. Qu and H. J. Fan, CrystEngComm, 2011, 13, 3506-3510.

$71 \mathrm{H}$. Kim and J. Cho, J. Mater. Chem., 2008, 18, 771-775.

72 Y. D. Ko, J. G. Kang, J. G. Park, S. Lee and D. W. Kim, Nanotechnology, 2009, 20, 455701.

73 W. Ren, C. Wang, L. Lu, D. Li, C. Cheng and J. Liu, J. Mater. Chem. A, 2013, 1, 13433-13438.

74 Q. Wan, E. N. Dattoli and W. Lu, Appl. Phys. Lett., 2007, 90, 222107.
75 Q. Tian, L. Li, J. Chen, L. Yang and S.-i. Hirano, J. Power Sources, 2018, 376, 1-10.

76 X. Zhu, H. Shi, J. Yin, H. Zhu, Y. Zhou, Y. Tang, P. Wu and T. Lu, RSC Adv., 2014, 4, 34417-34420.

77 L. Zhang, H. B. Wu and X. Wen Lou, Mater. Horiz., 2014, 1, 133-138.

78 S. Zhang, B. Yin, Y. Jiao, Y. Liu, F. Qu and X. Wu, Appl. Surf. Sci., 2014, 305, 626-629.

79 X. Zhao, B. Liu, C. Hu and M. Cao, Chemistry, 2014, 20, 467473.

80 Y. Zhu, H. Guo, H. Zhai and C. Cao, ACS Appl. Mater. Interfaces, 2015, 7, 2745-2753.

81 W. Wei, P. Du, D. Liu, H. Wang and P. Liu, J. Colloid Interface Sci., 2017, 503, 205-213.

82 B. Kumar, D. H. Lee, S. H. Kim, B. Yang, S. Maeng and S. W. Kim, J. Phys. Chem. C, 2010, 114, 11050-11055.

83 G. D. Park, J.-K. Lee and Y. C. Kang, Adv. Funct. Mater., 2017, 27, 222107.

84 J. H. Kim, K. M. Jeon, J.-S. Park and Y. C. Kang, J. Power Sources, 2017, 359, 363-370.

85 J.-S. Park, Y. J. Oh, J. H. Kim and Y. C. Kang, Mater. Charact., 2020, 161, 222107.

86 X. W. Lou, Y. Wang, C. Yuan, J. Y. Lee and L. A. Archer, Adv. Mater., 2006, 18, 2325-2329.

87 S. Ding and X. Wen Lou, Nanoscale, 2011, 3, 3586-3588.

88 H. Wang, F. Fu, F. Zhang, H.-E. Wang, S. V. Kershaw, J. Xu, S.-G. Sun and A. L. Rogach, J. Mater. Chem., 2012, 22, 21402148.

89 Y. Wang, T. Su, H. Chen, W. Liu, Y. Dong and S. Hu, Mater. Lett., 2014, 137, 241-244.

90 J. Qin, N. Zhao, C. Shi, E. Liu, F. He, L. Ma, Q. Li, J. Li and C. He, J. Mater. Chem. A, 2017, 5, 10946-10956.

91 W.-S. Kim, Y. Hwa, J.-H. Jeun, H.-J. Sohn and S.-H. Hong, J. Power Sources, 2013, 225, 108-112.

92 J. Zhang, H. Ren, J. Wang, J. Qi, R. Yu, D. Wang and Y. Liu, J. Mater. Chem. A, 2016, 4, 17673-17677.

93 L.-Y. Jiang, X.-L. Wu, Y.-G. Guo and L.-J. Wan, J. Phys. Chem. C, 2009, 113, 14213-14219.

94 H.-X. Zhang, C. Feng, Y.-C. Zhai, K.-L. Jiang, Q.-Q. Li and S.-S. Fan, Adv. Mater., 2009, 21, 2299-2304.

95 W. Dong, J. Xu, C. Wang, Y. Lu, X. Liu, X. Wang, X. Yuan, Z. Wang, T. Lin, M. Sui, I. W. Chen and F. Huang, Adv. Mater., 2017, 29, 1700136.

96 C. Zhang, X. Peng, Z. Guo, C. Cai, Z. Chen, D. Wexler, S. Li and H. Liu, Carbon, 2012, 50, 1897-1903.

97 W. Long, B. Fang, A. Ignaszak, Z. Wu, Y.-J. Wang and D. Wilkinson, Chem. Soc. Rev., 2017, 46, 7176-7190.

98 L. Noerochim, J.-Z. Wang, S.-L. Chou, H.-J. Li and H.-K. Liu, Electrochim. Acta, 2010, 56, 314-320.

99 X. W. Lou, D. Deng, J. Y. Lee and L. A. Archer, Chem. Mater., 2008, 20, 6562-6566.

100 Z. Wen, Q. Wang, Q. Zhang and J. Li, Adv. Funct. Mater., 2007, 17, 2772-2778.

101 D. Guan, J. Li, X. Gao and C. Yuan, $R S C A d v .$, 2015, 5, 5851458521. 
102 X. Zhou, W. Liu, X. Yu, Y. Liu, Y. Fang, S. Klankowski, Y. Yang, J. E. Brown and J. Li, ACS Appl. Mater. Interfaces, 2014, 6, 7434-7443.

103 J. S. Chen, Y. L. Cheah, Y. T. Chen, N. Jayaprakash, S. Madhavi, Y. H. Yang and X. W. Lou, J. Phys. Chem. C, 2009, 113, 20504-20508.

104 X. Zhao, Z. Zhang, F. Yang, Y. Fu, Y. Lai and J. Li, RSC Adv., 2015, 5, 31465-31471.

105 J. Cheng, H. Xin, H. Zheng and B. Wang, J. Power Sources, 2013, 232, 152-158.

106 H. Song, N. Li, H. Cui and C. Wang, J. Mater. Chem. A, 2013, 1, 7558-7562.

107 H. Liu, J. Huang, X. Li, J. Liu, Y. Zhang and K. Du, Appl. Surf. Sci., 2012, 258, 4917-4921.

108 L. Fan, X. Li, B. Yan, X. Li, D. Xiong, D. Li, H. Xu, X. Zhang and X. Sun, Appl. Energy, 2016, 175, 529-535.

109 H. Xu, L. Shi, Z. Wang, J. Liu, J. Zhu, Y. Zhao, M. Zhang and S. Yuan, ACS Appl. Mater. Interfaces, 2015, 7, 27486-27493.

110 J. Liu, J. Huang, L. Hao, H. Liu and X. Li, Ceram. Int., 2013, 39, 8623-8627.

111 H. Xu, J. Chen, D. Wang, Z. Sun, P. Zhang, Y. Zhang and X. Guo, Carbon, 2017, 124, 565-575.

112 B. Fang, J. H. Kim, M.-S. Kim and J.-S. Yu, Acc. Chem. Res., 2013, 46, 1397-1406.

113 Y. Xing, Y. Wang, C. Zhou, S. Zhang and B. Fang, ACS Appl. Mater. Interfaces, 2014, 6, 2561-2567.

114 J. Lu, D. Qi, C. Deng, X. Zhang and P. Yang, Nanoscale, 2010, 2, 1892-1900.

115 N. Du, Y. Chen, C. Zhai, H. Zhang and D. Yang, Nanoscale, 2013, 5, 4744-4750.

116 F. Li, G. Luo, J. Yu, W. Huang, D. Xu, W. Chen, X. Huang, S. Yang, Y. Fang and X. Yu, J. Alloys Compd., 2019, 773, 778-787.

117 X. Wu, W. Wu, Y. Zhou, X. Huang, W. Chen and Q. Wang, Powder Technol., 2015, 280, 119-123.

118 M. Huang, X. L. Zhao, F. Li, W. Li, B. Zhang and Y. X. Zhang, J. Mater. Chem. A, 2015, 3, 12852-12857.

119 J. Wang, H. Wang, T. Yao, T. Liu, Y. Tian, C. Li, F. Li, L. Meng and Y. Cheng, J. Colloid Interface Sci., 2020, 560, 546-554.

120 D. Deng, M. G. Kim, J. Y. Lee and J. Cho, Energy Environ. Sci., 2009, 2, 818-837.

121 Z. Yang, G. Du, Z. Guo, X. Yu, Z. Chen, T. Guo and R. Zeng, Nanoscale, 2011, 3, 4440-4447.

122 A. Ansari and D. Nematollahi, Appl. Catal., B, 2020, 261, 118226.

123 B. Zhao, F. Mattelaer, J. Kint, A. Werbrouck, L. Henderick, M. Minjauw, J. Dendooven and C. Detavernier, Electrochim. Acta, 2019, 320, 134604.

124 L. L. Si, Z. Q. Yuan, J. W. Liang, L. Hu, Y. C. Zhu and Y. T. Qian, J. Mater. Chem. A, 2014, 2, 9784-9791.

125 L.-J. Xue, Y.-F. Xu, L. Huang, F.-S. Ke, Y. He, Y.-X. Wang, G.-Z. Wei, J.-T. Li and S.-G. Sun, Electrochim. Acta, 2011, 56, 5979-5987.

126 H. El-Shinawi, A. S. Schulze, M. Neumeier, T. Leichtweiß and J. Janek, J. Phys. Chem. C, 2014, 118, 8818-8823.
127 Q. Tian, Y. Chen, F. Zhang, W. Zhang, Z. Sui and L. Yang, Appl. Surf. Sci., 2020, 511, 145625.

128 M. Jayalakshmi, M. M. Rao, N. Venugopal and K.-B. Kim, J. Power Sources, 2007, 166, 578-583.

129 Q. Guo, Z. Sun, M. Gao, Z. Tan, B. Zhang and D. S. Su, J. Energy Chem., 2013, 22, 347-355.

130 D. Wei, S. Zhong, H. Zhang, X. Zhang, C. Zhu, J. Duan, L. Li, Z. Chen, P. Liu, G. Zhang and H. Duan, Electrochim. Acta, 2018, 290, 312-321.

131 G. Wen, H. Liu, T. Liang, Y. Ouyang, L. Tan, R. Hu, J. Liu, Y. Zhang and M. Zhu, Electrochim. Acta, 2020, 334, 135640.

132 Y. Wang, H. Zhang, R. Hu, J. Liu, T. van Ree, H. Wang, L. Yang and M. Zhu, J. Alloys Compd., 2017, 693, 1174-1179.

133 W. Guo, Y. Wang, F. Zhang, S. Rao, P. Mao and D. Wang, Energy Fuels, 2020, 34, 2462-2470.

134 L. Si, Z. Yuan, J. Liang, L. Hu, Y. Zhu and Y. Qian, J. Mater. Chem. A, 2014, 2, 9784-9791.

135 D. Cao, H. Wang, B. Li, C. Li, S. Xie, A. L. Rogach and C. Niu, Electrochim. Acta, 2016, 216, 79-87.

136 K. Lee, S. Shin, T. Degen, W. Lee and Y. S. Yoon, Nano Energy, 2017, 32, 397-407.

137 X. Liu, F. Liu, Q. Sun, A. M. Ng, A. B. Djurisic, M. Xie, C. Liao, K. Shih and Z. Deng, ACS Appl. Mater. Interfaces, 2014, 6, 13478-13486.

138 H.-S. Oh, H. N. Nong and P. Strasser, Adv. Funct. Mater., 2015, 25, 1074-1081.

139 N. Wan, P. Yu, S. Sun, Q. Wu, T. Li and Y. Bai, Mater. Lett., 2014, 133, 168-170.

140 X. Liu, G. Zhou, S. W. Or and Y. Sun, RSC Adv., 2014, 4, 51389-51394.

141 A. Vignesh, A. S. Siddarth, O. S. Gokul and B. R. Babu, Int. J. Environ. Sci. Technol., 2014, 11, 1669-1678.

142 M. Ding, H. Liu, J. Zhu, X. Zhao, L. Pang, Y. Qin and L. Deng, Appl. Surf. Sci., 2018, 448, 389-399.

143 V. Vo, X. D. Nguyen Thi, Y.-S. Jin, G. Ly Thi, T. T. Nguyen, T. Q. Duong and S.-J. Kim, Chem. Phys. Lett., 2017, 674, 42-47.

144 J. Liu, Y. Li, X. Huang, R. Ding, Y. Hu, J. Jiang and L. Liao, J. Mater. Chem., 2009, 19, 1859-1864.

145 Y. J. Chen, X. Y. Xue, Y. G. Wang and T. H. Wang, Appl. Phys. Lett., 2005, 87, 233503.

146 W. Xu, K. Zhao, C. Niu, L. Zhang, Z. Cai, C. Han, L. He, T. Shen, M. Yan, L. Qu and L. Mai, Nano Energy, 2014, 8, 196-204.

147 J. Ye, H. Zhang, R. Yang, X. Li and L. Qi, Small, 2010, 6, 296306.

148 D. F. Zhang, L. D. Sun, J. L. Yin and C. H. Yan, Adv. Mater., 2003, 15, 1022-1025.

149 C. Yang, G. Zhang, L. Zhang and L. Ma, in Advances In Composites, Pts 1 and 2, ed. J. L. Bu, Z. Y. Jiang and S. Jiao, 2011, vol. 150-151, pp. 1387-1390.

150 C. Li, W. Wei, S. Fang, H. Wang, Y. Zhang, Y. Gui and R. Chen, J. Power Sources, 2010, 195, 2939-2944.

151 C. Guan, X. Wang, Q. Zhang, Z. Fan, H. Zhang and H. J. Fan, Nano Lett., 2014, 14, 4852-4858.

152 J. Y. Huang, L. Zhong, C. M. Wang, J. P. Sullivan, W. Xu, L. Q. Zhang, S. X. Mao, N. S. Hudak, X. H. Liu, 
A. Subramanian, H. Fan, L. Qi, A. Kushima and J. Li, Science, 2010, 330, 1515-1520.

153 R. Thomas and G. Mohan Rao, J. Mater. Chem. A, 2015, 3, 274-280.

154 J. Liu, Y. Li, X. Huang, R. Ding, Y. Hu, J. Jiang and L. Liao, J. Mater. Chem., 2009, 19, 1859-1864.

155 X. W. Lou and H. C. Zeng, Chem. Mater., 2002, 14, 47814789.

156 J. S. Chen, Y. L. Cheah, S. Madhavi and X. W. Lou, J. Phys. Chem. C, 2010, 114, 8675-8678.

157 X. Wang, W. Liu, H. Yang, X. Li, N. Li, R. Shi, H. Zhao and J. Yu, Acta Mater., 2011, 59, 1291-1299.

158 W. Zhang, L. L. Feng, H. Y. Chen and Y. Y. Zhang, Nano, 2019, 14, 1950109.

159 F. Paraguay-Delgado, W. Antunez-Flores, M. Miki-Yoshida, A. Aguilar-Elguezaba, P. Santiago, R. Diaz and J. A. Ascencio, Nanotechnology, 2005, 16, 688-694.

160 S. Ding, J. S. Chen and X. W. Lou, Chem.-Asian J., 2011, 6, 2278-2281.

161 N. Du, H. Zhang, B. Chen, X. Ma, X. Huang, J. Tu and D. Yang, Mater. Res. Bull., 2009, 44, 211-215.

162 X. Wang, J. Li, Z. Chen, L. Lei, X. Liao, X. Huang and B. Shi, J. Mater. Chem. A, 2016, 4, 18783-18791.

163 B. Cheng, J. M. Russell, W. S. Shi, L. Zhang and E. T. Samulski, J. Am. Chem. Soc., 2004, 126, 5972-5973.

164 G. Xi and J. Ye, Inorg. Chem., 2010, 49, 2302-2309.

165 L. Tan, M. S. Wang, Y. J. Liu, X. C. Xiao, L. Z. Fan and Y. D. Wang, Mater. Technol., 2013, 27, 191-195.

166 Z.-S. Wu, W. Ren, L. Wen, L. Gao, J. Zhao, Z. Chen, G. Zhou, F. Li and H.-M. Cheng, ACS Nano, 2010, 4, 3187-3194.

167 Q. Zhao, L. Ma, Q. Zhang, C. Wang and X. Xu, J. Nanomater., 2015, 2015, 850147.

168 J. Ye, H. Zhang, R. Yang, X. Li and L. Qi, Small, 2010, 6, 296306.

169 V. Kumar, J. H. Kim, C. Pendyala, B. Chernomordik and M. K. Sunkara, J. Phys. Chem. C, 2008, 112, 17750-17754.

170 Y. Han, X. Wu, Y. Ma, L. Gong, F. Qu and H. Fan, CrystEngComm, 2011, 13, 3506-3510.

171 S. Ding, D. Luan, F. Y. Boey, J. S. Chen and X. W. Lou, Chem. Commun., 2011, 47, 7155-7157.

172 D. Wang, X. Li, J. Wang, J. Yang, D. Geng, R. Li, M. Cai, T.-K. Sham and X. Sun, J. Phys. Chem. C, 2012, 116, 22149-22156.

173 B. Zhao, S.-Y. Huang, T. Wang, K. Zhang, M. M. F. Yuen, J.-B. Xu, X.-Z. Fu, R. Sun and C.-P. Wong, J. Power Sources, 2015, 298, 83-91.

174 L. Zhan, X. Zhou, J. Luo and X. Ning, Ceram. Int., 2019, 45, 6931-6936.

175 S. Hao, Y. Sun, Y. Liu, Y. Zhang and G. Hu, J. Alloys Compd., 2016, 689, 587-592.

176 S. Ramasamy, P. Nagamony and V. Chinnuswamy, Mater. Lett., 2018, 218, 295-298.

177 L.-L. Xing, Y.-Y. Zhao, J. Zhao, Y.-X. Nie, P. Deng, Q. Wang and X.-Y. Xue, J. Alloys Compd., 2014, 586, 28-33.

178 G. Z. Xing, Y. Wang, J. I. Wong, Y. M. Shi, Z. X. Huang, S. Li and H. Y. Yang, Appl. Phys. Lett., 2014, 105, 143905.
179 L. S. Fan, Z. K. Guo, Y. Zhang, X. Y. Zhang, M. X. Wang, Y. Y. Yin, N. Q. Zhang and K. N. Sun, Mater. Today Energy, 2019, 14, 6.

180 D. Y. A. Esquivel, R. K. Brown, S. Knohl and U. Schroeder, ChemElectroChem, 2020, 7, 1851-1859.

181 Y. Fu and A. Manthiram, Nano Energy, 2013, 2, 1107-1112. 182 X. Meng, J. Zhang, Y. Wang and H. Liu, Acta Chim. Sin., 2012, 70, 812-816.

183 L. Jabbour, M. Destro, C. Gerbaldi, D. Chaussy, N. Penazzi and D. Beneventi, J. Mater. Chem., 2012, 22, 3227-3233.

184 L. Chang, Z. Yi, Z. Wang, L. Wang and Y. Cheng, Appl. Surf. Sci., 2019, 484, 646-654.

185 M.-S. Wang, Z.-Q. Wang, Z.-L. Yang, Y. Huang, J. Zheng and X. Li, Electrochim. Acta, 2017, 240, 7-15.

186 R. Jia, J. Yue, Q. Xia, J. Xu, X. Zhu, S. Sun, T. Zhai and H. Xia, Energy Storage Mater., 2018, 13, 303-311.

187 L. Fan, Z. Guo, Y. Zhang, X. Zhang, M. Wang, Y. Yin, N. Zhang and K. Sun, Mater. Today Energy, 2019, 14, E28E62.

188 L. Vayssieres, Adv. Mater., 2003, 15, 464-466.

189 W.-w. Zhan, Q. Kuang, J.-z. Zhou, X.-j. Kong, Z.-x. Xie and L.-s. Zheng, J. Am. Chem. Soc., 2013, 135, 1926-1933.

190 J. Liu, S. Z. Qiao, S. B. Hartono and G. Q. Lu, Angew. Chem., Int. Ed., 2010, 49, 4981-4985.

191 J. Liu, T. Yang, D.-W. Wang, G. Q. Lu, D. Zhao and S. Z. Qiao, Nat. Commun., 2013, 4, 2798.

192 H. X. Yang, J. F. Qian, Z. X. Chen, X. P. Ai and Y. L. Cao, J. Phys. Chem. C, 2007, 111, 14067-14071.

193 C.-Y. Chang-Chien, C.-H. Hsu, T.-Y. Lee, C.-W. Liu, S.-H. Wu, H.-P. Lin, C.-Y. Tang and C.-Y. Lin, Eur. J. Inorg. Chem., 2007, 2007, 3798-3804.

194 Y. Yin, S. Xin, L. Wan, C. Li and Y. Guo, Sci. China: Chem., 2012, 55, 1314-1318.

195 L. Zhang, H. B. Wu, B. Liu and X. W. Lou, Energy Environ. Sci., 2014, 7, 1013-1017.

196 Y. Liu, H. Dong and M. L. Liu, Adv. Mater., 2004, 16, 353356.

197 T. Wang, H. Xu, Y. Wang, Y. Zeng and B. Liu, Mater. Lett., 2020, 264, 127320.

198 L. Zhou, J. Zhang, Y. Wu, W. Wang, H. Ming, Q. Sun, L. Wang, J. Ming and H. N. Alshareef, Adv. Energy Mater., 2019, 9, 1902194.

199 J. S. Chen, C. M. Li, W. W. Zhou, Q. Y. Yan, L. A. Archer and X. W. Lou, Nanoscale, 2009, 1, 280-285.

200 S. Liu, M. Xie, Y. Li, X. Guo, W. Ji, W. Ding and C. Au, Sens. Actuators, B, 2010, 151, 229-235.

201 Y.-Z. Wu, S. Brahma, S.-C. Weng, C.-C. Chang and J.-L. Huang, J. Alloys Compd., 2020, 818, 152889.

202 G. D. Park, J.-K. Lee and Y. C. Kang, Adv. Funct. Mater., 2017, 27, 1603399.

203 G. D. Park, J. H. Kim and Y. C. Kang, Nanoscale, 2018, 10, 13531-13538.

204 J. S. Cho and Y. C. Kang, Small, 2015, 11, 4673-4681.

205 L. Liu, F. Xie, J. Lyu, T. Zhao, T. Li and B. G. Choi, J. Power Sources, 2016, 321, 11-35. 
206 H. Hu, L. Wu, P. Gebhardt, X. Zhang, A. Cherevan, B. Gerke, R. Pöttgen, A. Balducci, S. Passerini and D. Eder, CrystEngComm, 2017, 19, 6454-6463.

207 W. Tian, C. Zhang, T. Zhai, S.-L. Li, X. Wang, M. Liao, K. Tsukagoshi, D. Golberg and Y. Bando, Chem. Commun., 2013, 49, 3739-3741.

208 Y. Kang, Z. Li, K. Xu, X. He, S. Wei and Y. Cao, J. Alloys Compd., 2019, 779, 728-734.

209 S. Ding, J. S. Chen, G. Qi, X. Duan, Z. Wang, E. P. Giannelis, L. A. Archer and X. W. Lou, J. Am. Chem. Soc., 2011, 133, 2123.

210 J. Deng, Y. Chen, J. Ma, E. Zhang and T. Wang, J. Nanosci. Nanotechnol., 2013, 13, 4297-4301.

211 X. M. Yin, C. C. Li, M. Zhang, Q. Y. Hao, S. Liu, L. B. Chen and T. H. Wang, J. Phys. Chem. C, 2010, 114, 8084-8088.

212 S. P. Kim, M. Y. Choi and H. C. Choi, Appl. Surf. Sci., 2015, 357, 302-308.

213 Z. Lu and H. Wang, CrystEngComm, 2014, 16, 550-555.

214 H. Song, N. Li, H. Cui and C. Wang, Electrochim. Acta, 2014, 120, 46-51.

215 J. Deng, Y. Dai, Z. Xiao, S. Song, H. Dai, L. Li and J. Li, Nanomaterials, 2020, 10, 249.

216 Q. H. Tian, Y. B. Chen, W. Zhang, Z. Y. Sui and L. Yang, J. Alloys Compd., 2020, 820, 8.

217 X. Zhou, L. Yu and X. W. Lou, Nanoscale, 2016, 8, 83848389.

218 A. Yang, X. Tao, R. Wang, S. Lee and C. Surya, Appl. Phys. Lett., 2007, 91, 133110.

219 X.-H. Li, H.-C. Huang, L. Ling, X.-Y. Wang, J.-R. Zhang and L. Gao, Chin. J. Inorg. Chem., 2011, 27, 781-784.

220 M. Xia, H.-Y. Guo and B. Yang, Fullerenes, Nanotubes, Carbon Nanostruct., 2018, 26, 76-79.

221 P. Wu, N. Du, H. Zhang, J. Yu, Y. Qi and D. Yang, Nanoscale, 2011, 3, 746-750.

222 G. Du, C. Zhong, P. Zhang, Z. Guo, Z. Chen and H. Liu, Electrochim. Acta, 2010, 55, 2582-2586.

223 K. Liu, S. Zhu, X. Dong, H. Huang and M. Qi, Adv. Mater. Interfaces, 2020, 7, 1901916.

224 Y.-H. Jin, K.-M. Min, S.-D. Seo, H.-W. Shim and D.-W. Kim, J. Phys. Chem. C, 2011, 115, 22062-22067.

225 G. Liang, X. Sun, J. Lai, C. Wei, Y. Huang and H. Hu, J. Electroanal. Chem., 2019, 853, 113401.

226 Q. Tian, Y. Tian, Z. Zhang, L. Yang and S.-i. Hirano, J. Power Sources, 2015, 291, 173-180.

227 M. Liu, S. Zhang, H. C. Dong, X. Chen, S. Gao, Y. P. Sun, W. H. Li, J. Q. Xu, L. W. Chen, A. B. Yuan and W. Lu, ACS Sustainable Chem. Eng., 2019, 7, 4195-4203.

228 Q. Liu, Y. Dou, B. Ruan, Z. Sun, S. L. Chou and S. X. Dou, Chemistry, 2016, 22, 5853-5857.

229 Y. Wan, Y. Sha, W. Deng, Q. Zhu, Z. Chen, X. Wang, W. Chen, G. Xue and D. Zhou, Electrochim. Acta, 2015, 167, 69-74.

230 F. R. He, Q. Xu, B. P. Zheng, J. Zhang, Z. G. Wu, Y. J. Zhong, Y. X. Chen, W. Xiang, B. H. Zhong and X. D. Guo, RSC Adv., 2020, 10, 6035-6042.

231 L. Yuan, K. Konstantinov, G. X. Wang, H. K. Liu and S. X. Dou, J. Power Sources, 2005, 146, 180-184.
232 H. Liu, D. Long, X. Liu, W. Qiao, L. Zhan and L. Ling, Electrochim. Acta, 2009, 54, 5782-5788.

233 J. Shi, N. Lin, D. Liu, Y. Wang and H. Lin, J. Electroanal. Chem., 2020, 857, 113634.

234 X. Sun, J. Liu and Y. Li, Chem. Mater., 2006, 18, 3486-3494.

235 H. Qiao, Z. Zheng, L. Zhang and L. Xiao, J. Mater. Sci., 2008, 43, 2778-2784.

236 X. Tao, Q. Tian, L. Yang and Y. Xiang, Mater. Lett., 2017, 202, 107-110.

237 P. Wu, N. Du, H. Zhang, C. Zhai and D. Yang, ACS Appl. Mater. Interfaces, 2011, 3, 1946-1952.

238 Y. Chen, Q. Z. Huang, J. Wang, Q. Wang and J. M. Xue, J. Mater. Chem., 2011, 21, 17448-17453.

239 M.-S. Wang, M. Lei, Z.-Q. Wang, X. Zhao, J. Xu, W. Yang, Y. Huang and X. Li, J. Power Sources, 2016, 309, 238-244.

240 Z.-G. Wu, J.-T. Li, Y.-J. Zhong, J. Liu, X.-D. Guo, L. Huang, B.-H. Zhong and S.-G. Sun, J. Alloys Compd., 2015, 620, 407-412.

241 X. Wang, H. Fan, P. Ren and M. Li, RSC Adv., 2014, 4, 10284-10289.

242 X. Zhao, T. Wen, J. Zhang, J. Ye, Z. Ma, H. Yuan, X. Ye and Y. Wang, RSC Adv., 2017, 7, 21678-21685.

243 J. Yuan, C. Chen, Y. Hao, X. Zhang, B. Zou, R. Agrawal, C. Wang, H. Yu, X. Zhu, Y. Yu, Z. Xiong, Y. Luo, H. Li and Y. Xie, J. Alloys Compd., 2017, 691, 34-39.

244 C. Ma, W. Zhang, Y. S. He, Q. Gong, H. Che and Z. F. Ma, Nanoscale, 2016, 8, 4121-4126.

245 S.-L. Yang, B.-H. Zhou, M. Lei, L.-P. Huang, J. Pan, W. Wu and H.-B. Zhang, Chin. Chem. Lett., 2015, 26, 1293-1297.

246 Yiliguma, Z. Wang, C. Yang, A. Guan, L. Shang, A. M. AlEnizi, L. Zhang and G. Zheng, J. Mater. Chem. A, 2018, 6, 20121-20127.

247 S. Nam, S. Kim, S. Wi, H. Choi, S. Byun, S.-M. Choi, S.-I. Yoo, K. T. Lee and B. Park, J. Power Sources, 2012, 211, 154-160.

248 X. Ji, X. Huang, J. Liu, J. Jiang, X. Li, R. Ding, Y. Hu, F. Wu and Q. Li, Nanoscale Res. Lett., 2010, 5, 649-653.

249 L. Yu, D. Cai, H. Wang and M.-M. Titirici, RSC Adv., 2013, 3, 17281-17286.

250 X. W. Lou, J. S. Chen, P. Chen and L. A. Archer, Chem. Mater., 2009, 21, 2868-2874.

251 F. M. Courtel, E. A. Baranova, Y. Abu-Lebdeh and I. J. Davidson, J. Power Sources, 2010, 195, 2355-2361.

252 G.-L. Xu, S.-R. Chen, J.-T. Li, F.-S. Ke, L. Huang and S.-G. Sun, J. Electroanal. Chem., 2011, 656, 185-191.

253 W. Zhang and H. Liu, Neurocomputing, 2017, 247, 183-191.

254 C. Hernández-Rentero, V. Marangon, M. Olivares-Marín, V. Gómez-Serrano, Á. Caballero, J. Morales and J. Hassoun, J. Colloid Interface Sci., 2020, 573, 396-408.

255 Y. Dou, X. Liu, K. Yu, X. Wang, W. Liu, J. Liang and C. Liang, Diamond Relat. Mater., 2019, 98, 107514.

256 L.-L. Hu, L.-P. Yang, D. Zhang, X.-S. Tao, C. Zeng, A.-M. Cao and L.-J. Wan, Chem. Commun., 2017, 53, 11189-11192.

257 Q. Tian, F. Zhang, W. Zhang and L. Yang, Electrochim. Acta, 2019, 307, 393-402. 
258 Z. Rujia, Z. Zhang, L. Jiang, K. Xu, Q. Tian, S. Xue, J. Hu, Y. Bando and D. Golberg, J. Mater. Chem., 2012, 22, 19196-19201.

259 W. Zhang, M. Li, X. Xiao, X. Huang, Y. Jiang, X. Fan and L. Chen, J. Alloys Compd., 2017, 727, 1-7.

260 Z. S. Wu, Y. Sun, Y. Z. Tan, S. Yang, X. Feng and K. Mullen, J. Am. Chem. Soc., 2012, 134, 19532-19535.

261 S. Stankovich, D. A. Dikin, R. D. Piner, K. A. Kohlhaas, A. Kleinhammes, Y. Jia, Y. Wu, S. T. Nguyen and R. S. Ruoff, Carbon, 2007, 45, 1558-1565.

262 A. H. Castro Neto, F. Guinea, N. M. R. Peres, K. S. Novoselov and A. K. Geim, Rev. Mod. Phys., 2009, 81, 109-162.

263 A. K. Geim, Science, 2009, 324, 1530-1534.

264 S.-y. Zuo, Z.-g. Wu, S.-k. Li, D. Yan, Y.-h. Liu, F.-y. Wang, R.-f. Zhuo, B.-s. Geng, J. Wang and P.-x. Yan, RSC Adv., 2017, 7, 18054-18059.

265 D. Zhou, X. Li, L.-Z. Fan and Y. Deng, Electrochim. Acta, 2017, 230, 212-221.

266 M. Zhang, Z. Sun, T. Zhang, D. Sui, Y. Ma and Y. Chen, Carbon, 2016, 102, 32-38.

267 Z. Li, G. Wu, S. Deng, S. Wang, Y. Wang, J. Zhou, S. Liu, W. Wu and M. Wu, Chem. Eng. J., 2016, 283, 1435-1442.

268 J. Han, D. Kong, W. Lv, D. M. Tang, D. Han, C. Zhang, D. Liu, Z. Xiao, X. Zhang, J. Xiao, X. He, F. C. Hsia, C. Zhang, Y. Tao, D. Golberg, F. Kang, L. Zhi and Q. H. Yang, Nat. Commun., 2018, 9, 402.

269 S. Shi, T. Deng, M. Zhang and G. Yang, Electrochim. Acta, 2017, 246, 1104-1111.

270 Z.-S. Wu, W. Ren, L. Xu, F. Li and H.-M. Cheng, ACS Nano, 2011, 5, 5463-5471.

271 D. D. Liu, Z. Y. Wei, B. Zhong, L. M. Liu, T. Zhang, X. M. Duan, M. Chen, H. T. Wang and X. X. Huang, Appl. Surf. Sci., 2020, 519, 5.

272 Y. Huang, R. Yu, G. Mao, W. Yu, Z. Ding, Y. Cao, J. Zheng, D. Chu and H. Tong, J. Alloys Compd., 2020, 841, 155670.

273 H. Zhang and S. Liu, J. Alloys Compd., 2020, 842, 155873.

274 K. Wang and Z. Li, J. Nanosci. Nanotechnol., 2020, 20, 76737679.

275 D. Liu, Z. Wei, B. Zhong, L. Liu, T. Zhang, X. Duan, M. Chen, H. Wang and X. Huang, Appl. Surf. Sci., 2020, 519, 146190.

276 X. Zuo, B. Li, K. Chang, H. Tang and Z. Chang, RSC Adv., 2017, 7, 53126-53134.

277 D. Usachov, O. Vilkov, A. Gruneis, D. Haberer, A. Fedorov, V. K. Adamchuk, A. B. Preobrajenski, P. Dudin, A. Barinov, M. Oehzelt, C. Laubschat and D. V. Vyalikh, Nano Lett., 2011, 11, 5401-5407.

278 H. Song, N. Li, H. Cui and C. Wang, Nano Energy, 2014, 4, 81-87.

279 X. Zhou, L. J. Wan and Y. G. Guo, Adv. Mater., 2013, 25, 2152-2157.

280 N. Wu, W. Du, X. Gao, L. Zhao, G. Liu, X. Liu, H. Wu and Y. B. He, Nanoscale, 2018, 10, 11460-11466.

281 J. P. Paraknowitsch and A. Thomas, Energy Environ. Sci., 2013, 6, 2839-2855.
282 K. Wu, B. Shi, L. Qi, Y. Mi, B. Zhao, C. Yang, Q. Wang, H. Tang, J. Lu, W. Liu and H. Zhou, Electrochim. Acta, 2018, 291, 24-30.

283 U. N. Maiti, W. J. Lee, J. M. Lee, Y. Oh, J. Y. Kim, J. E. Kim, J. Shim, T. H. Han and S. O. Kim, Adv. Mater., 2014, 26, 4067.

284 A. Verchere, S. Mishra, E. Jeanneau, H. Guillon, J.-M. Decams and S. Daniele, Inorg. Chem., 2020, 59, 7167-7180.

285 Y. Sun, S. Cheng, Z. Yu, L. Li, C. Li and J. Yang, J. Alloys Compd., 2020, 834, 155184.

286 M. Maleki, Acta Phys. Pol., A, 2020, 137, 272-275.

287 W. Wang, Y. Liu and S. Liu, Cryst. Growth Des., 2020, 20, 2742-2752.

288 C. R. Ma, W. M. Zhang, Y. S. He, Q. Gong, H. Y. Che and Z. F. Ma, Nanoscale, 2016, 8, 4121-4126.

289 L. Wen, F. Li and H.-M. Cheng, Adv. Mater., 2016, 28, 43064337.

290 B. A. Zhang, Q. B. Zheng, Z. D. Huang, S. W. Oh and J. K. Kim, Carbon, 2011, 49, 4524-4534.

291 J. Wang, F. Fang, T. Yuan, J. Yang, L. Chen, C. Yao, S. Zheng and D. Sun, ACS Appl. Mater. Interfaces, 2017, 9, 3544-3553.

292 S. K. Kulshreshtha, M. M. Gadgil and R. Sasikala, Catal. Lett., 1996, 37, 181-185.

293 A. Jayalakshmi, N. Venugopal, K. P. Raja and M. M. Rao, J. Power Sources, 2006, 158, 1538-1543.

294 S.-H. Shin, J.-M. Song, S.-W. Kim, J.-K. Shin, S.-M. Lee, J.-C. Ro and S.-J. Suh, Phys. Status Solidi A, 2020, 217, 1900996

295 D. Shao, X. Zhang, Z. Wang, Y. Zhang, G. Tan and W. Yan, Appl. Surf. Sci., 2020, 515, 146003.

296 D. Shao, Y. Zhang, W. Lyu, X. Zhang, G. Tan, H. Xu and W. Yan, J. Hazard. Mater., 2020, 390, 122174.

297 M. Liu, H. Fan, O. Zhuo, J. Chen, Q. Wu, L. Yang, L. Peng, X. Wang, R. Che and Z. Hu, Nano Energy, 2020, 68, 104368.

298 G. Luo, W. Liu, S. Zeng, C. Zhang, X. Yu, Y. Fang and L. Sun, Electrochim. Acta, 2015, 184, 219-225.

299 Y. Liu, Y. Jiao, B. Yin, S. Zhang, F. Qu and X. Wu, J. Mater. Chem. A, 2015, 3, 3676-3682.

300 Q. Tian, J. Yan, L. Yang and J. Chen, Electrochim. Acta, 2018, 282, 38-47.

301 H. Xie, M. Chen and L. Wu, Small, 2017, 13, 1604283.

302 H. Yang, T. Song, S. Lee, H. Han, F. Xia, A. Devadoss, W. Sigmund and U. Paik, Electrochim. Acta, 2013, 91, 275281.

303 J. S. Chen, C. M. Li, W. W. Zhou, Q. Y. Yan, L. A. Archer and X. W. Lou, Nanoscale, 2009, 1, 280-285.

304 Y. Wang, J. Xu, H. Wu, M. Xu, Z. Peng and G. Zheng, J. Mater. Chem., 2012, 22, 21923-21927.

305 D.-F. Zhang, L.-D. Sun, C.-J. Jia, Z.-G. Yan, L.-P. You and C.-H. Yan, J. Am. Chem. Soc., 2005, 127, 13492-13493.

306 W.-W. Wang, Mater. Res. Bull., 2008, 43, 2055-2059.

307 W. Zhou, C. Cheng, J. Liu, Y. Y. Tay, J. Jiang, X. Jia, J. Zhang, H. Gong, H. H. Hng, T. Yu and H. J. Fan, Adv. Funct. Mater., 2011, 21, 2439-2445.

308 Z. X. Chen, M. Zhou, Y. L. Cao, X. P. Ai, H. X. Yang and J. Liu, Adv. Energy Mater., 2012, 2, 95-102. 
309 T. Yuan, Y. Jiang, Y. Li, D. Zhang and M. Yan, Electrochim. Acta, 2014, 136, 27-32.

310 W. Wu, Y. Zhao, J. Li, C. Wu and L. Guan, J. Energy Chem., 2014, 23, 376-382.

311 J. Guo, H. Zhu, Y. Sun, L. Tang and X. Zhang, J. Mater. Chem. A, 2016, 4, 16101-16107.

312 G. D. Park, J. K. Lee and Y. C. Kang, J. Mater. Chem. A, 2017, 5, 25319-25327.

313 B.-R. Koo, D.-H. Lee, H.-J. Ahn and Y.-E. Sung, J. Nanosci. Nanotechnol., 2016, 16, 10558-10562.

314 J. Ma, J. Li, S. Yang, H. Lu, L. Liu and R. Wang, J. Power Sources, 2020, 453, 227866.

315 Y. Qi, H. Zhang, N. Du, C. Zhai and D. Yang, RSC Adv., 2012, 2, 9511-9516.

316 J. Hou, C. Cao, F. Idrees and X. Ma, ACS Nano, 2015, 9, 2556-2564.

317 Y. N. Sun, M. Goktas, L. Zhao, P. Adelhelm and B. H. Han, J. Colloid Interface Sci., 2020, 572, 122-132.

318 X. Li, Y. Zhang, T. Li, Q. Zhong, H. Li and J. Huang, Electrochim. Acta, 2014, 147, 40-46.

319 W. Tao, M. Wang, B. Zhu, W. Huo, R. Yang, H. Xiong, H. Tang, Z. Wei and Y. Wang, Electrochim. Acta, 2020, 334, 135569.

320 B. Huang, Z. Pan, X. Su and L. An, J. Power Sources, 2018, 395, 41-59.

321 H. Zhou, Y. Zhong, Z. He, L. zhang, J. Wang, J. Zhang and C.-n. Cao, Appl. Surf. Sci., 2014, 314, 1-6.

322 J. Ding, X. Gao, L. Cha, M.-Q. Cai and J. Ma, RSC Adv., 2016, 6, 108310-108314.

323 Q. Tian, Z. Zhang, L. Yang and S.-i. Hirano, RSC Adv., 2015, 5, 40303-40309.

324 F. Yang, Y. Zhu, X. Li, C. Lai, W. Guo and J. Ma, RSC Adv., 2015, 5, 98717-98720.

325 Y. Xing, S. Wang, B. Fang, G. Song, D. P. Wilkinson and S. Zhang, J. Power Sources, 2018, 385, 10-17.

326 R. D. Shannon, Acta Crystallogr., Sect. A: Cryst. Phys., Diffr., Theor. Gen. Crystallogr., 1976, 32, 751-767.

327 L. Zhou, H. Guo, T. Li, W. Chen, L. Liu, J. Qiao and J. Zhang, Sci. Rep., 2015, 5, 15252.

328 Z. Yang, G. Du, Z. Guo, X. Yu, Z. Chen, T. Guo and R. Zeng, Nanoscale, 2011, 3, 4440-4447.

329 Z. Yi, Q. Han, P. Zan, Y. Cheng, Y. Wu and L. Wang, J. Mater. Chem. A, 2016, 4, 12850-12857.

330 J. Y. Cheong, C. Kim, J. S. Jang and I.-D. Kim, RSC Adv., 2016, 6, 2920-2925.

331 A. Xu, X. Dai, K. Wei, W. Han, J. Li, X. Sun, J. Shen and L. Wang, RSC Adv., 2017, 7, 37806-37814.

332 L. Xu, Y. Wang and W. Zhang, RSC Adv., 2019, 9, 3924239251.
333 Z. Yang, G. Du, Q. Meng, Z. Guo, X. Yu, Z. Chen, T. Guo and R. Zeng, RSC Adv., 2011, 1, 1834-1840.

334 H. Yoo, G. Lee and J. Choi, $R S C A d v$., 2019, 9, 6589-6595.

335 Z. Yang, Q. Meng, Z. Guo, X. Yu, T. Guo and R. Zeng, J. Mater. Chem. A, 2013, 1, 10395-10402.

336 L. He, C. Wang, X. Yao, R. Ma, H. Wang, P. Chen and K. Zhang, Carbon, 2014, 75, 345-352.

337 Z. Lu and H. Wang, CrystEngComm, 2014, 16, 550-555.

338 Y. Tang, D. Wu, S. Chen, F. Zhang, J. Jia and X. Feng, Energy Environ. Sci., 2013, 6, 2447-2451.

339 S. Bai and X. Shen, RSC Adv., 2012, 2, 64-98.

340 R. K. Singh, R. Kumar and D. P. Singh, RSC Adv., 2016, 6, 64993-65011.

341 H. F. Xiang, Z. D. Li, K. Xie, J. Z. Jiang, J. J. Chen, P. C. Lian, J. S. Wu, Y. Yu and H. H. Wang, RSC Adv., 2012, 2, 67926799.

342 G. Zhao, T. Wen, C. Chen and X. Wang, RSC Adv., 2012, 2, 9286-9303.

343 A. Abbasnezhad, H. Asgharzadeh, A. Ansari Hamedani and S. Hayat Soytas, Dalton Trans., 2020, 49, 5890-5897.

344 S. Bai, S. Chen, X. Shen, G. Zhu and G. Wang, RSC Adv., 2012, 2, 10977-10984.

345 L. Tao, J. Zai, K. Wang, Y. Wan, H. Zhang, C. Yu, Y. Xiao and X. Qian, RSC Adv., 2012, 2, 3410-3415.

346 C. Y. Du, M. Chen, X. Y. Cao, G. P. Yin and P. F. Shi, Electrochem. Commun., 2009, 11, 496-498.

347 J. Zhao, W. Shan, X. Xia, Q. Wang and L. Xing, Sci. China: Technol. Sci., 2014, 57, 1081-1084.

348 J. Sun, Q. Wang, Q. Wang, D. A. Zhang, L. L. Xing and X. Y. Xue, Sci. Adv. Mater., 2016, 8, 1280-1285.

349 R. Cai, X. Yu, X. Liu and Z. Shao, J. Power Sources, 2010, 195, 8244-8250.

350 Y. Hui, L. Cao, Z. Xu, J. Huang, H. Ouyang and J. Li, J. Electroanal. Chem., 2016, 763, 45-50.

351 J. Gao, C. Jiang, J. Ying and C. Wan, J. Power Sources, 2006, 155, 364-367.

352 K. Song, D.-H. Seo, M. R. Jo, Y.-I. Kim, K. Kang and Y.-M. Kang, J. Phys. Chem. Lett., 2014, 5, 1368-1373.

353 F. Mueller, D. Bresser, V. S. K. Chakravadhanula and S. Passerini, J. Power Sources, 2015, 299, 398-402.

354 A. Chen, S. J. Xia, H. Y. Pan, J. H. Xi, H. Y. Qin, H. W. Lu and Z. G. Ji, J. Electroanal. Chem., 2018, 824, 169-174.

355 Y. H. Cui and Y. J. Feng, J. Mater. Sci., 2005, 40, 4695-4697. 356 V. Subramanian, K. I. Gnanasekar and B. Rambabu, Solid State Ionics, 2004, 175, 181-184.

357 T. Jia, J. Chen, Z. Deng, F. Fu, J. Zhao, X. Wang and F. Long, Mater. Sci. Eng., B, 2014, 189, 32-37. 